Revue des patrimoines

25 | 2014

Le patrimoine de la Grande Guerre

\title{
Un patrimoine mémoriel en expansion. André Pézard et la Grande Guerre : un éternel retour
}

\section{Elsa Marguin-Hamon}

\section{(2) OpenEdition}

1 Journals

\section{Édition électronique}

URL : http://journals.openedition.org/insitu/11666

DOI : 10.4000/insitu. 11666

ISSN : 1630-7305

Éditeur

Ministère de la Culture

\section{Référence électronique}

Elsa Marguin-Hamon, « Un patrimoine mémoriel en expansion. André Pézard et la Grande Guerre : un éternel retour », In Situ [En ligne], 25 | 2014, mis en ligne le 22 décembre 2014, consulté le 25 juin 2020. URL : http://journals.openedition.org/insitu/11666; DOI : https://doi.org/10.4000/insitu.11666

Ce document a été généré automatiquement le 25 juin 2020.

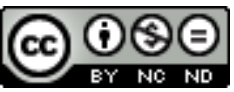

In Situ Revues des patrimoines est mis à disposition selon les termes de la licence Creative Commons Attribution - Pas d'Utilisation Commerciale - Pas de Modification 4.0 International. 


\title{
Un patrimoine mémoriel en expansion. André Pézard et la Grande Guerre : un éternel retour
}

\author{
Elsa Marguin-Hamon
}

«Il dit : "Comment ? Était-ce là la vie ? Allons !
Recommençons encore une fois !" "
(Nietzsche, Ainsi parlait Zarathoustra, III)

1 Au premier rang des récits de guerre que Jean Norton Cru, dans Témoins (19291), tient pour dignes de foi, et même à cet égard exemplaires, figure l'ouvrage d'André Pézard intitulé Nous autres à Vauquois (1918). Les catégories et la sélection élaborées par Cru, qui lui valent les foudres d'une partie de la critique littéraire ${ }^{2}$, relèvent, certes, d'une approche largement positiviste, distinguant de manière un peu simple un récit à la première personne, peu enclin aux effets de style - signe de sa sincérité - d'une «littérature littératurante ${ }^{3}$ » à laquelle il faudrait refuser toute valeur testimoniale. L'auteur de Témoins ne tient ou ne veut pas tenir compte, ce faisant, du travail proprement littéraire auquel se livre le puissant styliste qu'est André Pézard dans Vauquois - un styliste qui imprime à toute son œuvre, à la fois érudite, philologique, littéraire, une signature unique ; un styliste qui forge pour traduire Dante une langue à part, ancien français renouvelé pour les besoins de la poétique dantesque.

2 Pour autant, le travail d'écriture de Nous autres à Vauquois, tout comme la véracité du récit saluée dans Témoins, est rendu possible par la constitution antérieure, sur place si l'on peut dire, d'une documentation dont les archives gardent la trace, offrant des ressources inexploitées et invisibles à qui s'arrête au livre publié. Et Vauquois n'a rien d'une fin, d'un aboutissement ultime : il est ouverture vers autre chose qui constitue les couches supérieures d'un sédiment archivistique unique autour de la mémoire de la Grande Guerre.

3 À l'intérieur du fonds réuni aux Archives nationales depuis 2012 sous la cote $691 \mathrm{AP}$, les archives inédites de la Grande Guerre font partie des papiers demeurés dans la famille d'André Pézard jusqu'en 2011. Les manuscrits du livre, la presse et les retours de 
lecteurs, ainsi que l'iconographie "officielle" des rééditions ont en revanche "transité » par le Collège de France, qui entreprit dès 1973 la collecte des travaux préparatoires de ses enseignants et chercheurs avant de déposer à l'IMEC (2001) les ensembles ainsi rassemblés. Cette répartition initiale, qui recouvre, à gros traits, la séparation entre intime et publié, semble correspondre à deux statuts différents, deux destinations disjointes assignées à deux parties du fonds, distinguées par les soins de Fanette Pézard, sans doute sur la foi des instructions de son père ${ }^{4}$, après la mort de ce dernier.

4 La Grande Guerre constitue, de part et d'autre, l'un des «fils rouges » du fonds : elle cristallise en effet une production archivistique (écrits personnels ou publiés, travaux préparatoires aux rééditions, documentation, correspondance passive voire active, implication dans les comités mémoriels et associations d'anciens combattants...) qui ne s'arrête pratiquement qu'avec la mort d'André Pézard en 1984.

5 Carnets, lettres, photos, manuscrits : l'ensemble des documents concernant la Grande Guerre dans le fonds Pézard est à la fois divers, voire hétéroclite, et foisonnant. Nous ne prétendons pas ici en faire l'inventaire exhaustif, mais tenterons de rendre compte de cette variété en tant qu'elle est partie prenante des processus mémoriels, aux temporalités distinctes, dont le fonds demeure le principal témoin, trente ans après la mort de Pézard. S'y superposent en effet des écrits tenus au moment même des combats : notes prises sur le vif, sous forme de carnets, correspondances que Pézard ordonne et documente de manière extrêmement minutieuse ; des récits élaborés par lui après la démobilisation, témoignant d'un retraitement proprement littéraire du matériau archivistique constitué ; un ensemble de documents visant à amender et compléter Vauquois au gré de ses traductions, rééditions, des années 1930 à 1970. À cette documentation s'attache en particulier un faisceau de témoignages allogènes lettres, mémoires, photographies - que Pézard reçoit et garde, constituant ses archives en conservatoire de la mémoire privée de la Grande Guerre.

\section{Embrasser la guerre sur le vif}

6 Les retours à présent observables de la grande collecte initiée fin 2013 confirment une tendance dont les historiens avaient commencé de mesurer l'ampleur: un foisonnement sans précédent de récits, de témoignages multiformes, dès les premiers jours de la guerre - voire dans les semaines qui précèdent -, rendant compte, au prisme d'expériences toujours individuelles sinon singulières, des événements vécus ou observés. Nombre des hommes, issus de classes d'âge bénéficiaires de l'enseignement primaire public et obligatoire, disposent alors, il est vrai, des moyens de transcrire sur le vif la réalité d'expériences vécues, lorsqu'ils n'usent pas du dessin ou de la photographie pour ce faire. Il n'est en effet pas rare que les jeunes (ou moins jeunes) mobilisés partent au front munis de journaux de format de poche, de carnets de croquis et d'appareils photos dont les pellicules sont transmises pour être développées aux proches restés à l'arrière.

7 André Pézard est de ceux-là. Tout juste admis au concours de l'École normale supérieure de la rue d'Ulm, le 25 juillet 1914, il est mobilisé, le 10 août, et part faire ses classes. Il rejoint au début de 1915 le $46^{\mathrm{e}}$ d'infanterie où il servira comme souslieutenant, puis lieutenant. Il participe aux campagnes de Vauquois, de l'Argonne et de la Somme avant d'être blessé en septembre 1916. 
8 Ce tout jeune italianiste, lecteur assidu et averti des classiques grecs et latins autant que de l'œuvre de Dante et des grands auteurs italiens, qu'il traduira par la suite, germaniste également depuis sa sixième au lycée Montaigne n'en est pas à ses premiers essais de diariste. Il tient en effet, depuis 1909, deux types distincts, quoique parallèles, de carnets.

\section{Déjà avant la guerre... les journaux intimes comme antichambre de l'expérience de vie et d'écriture à venir}

Figure 1

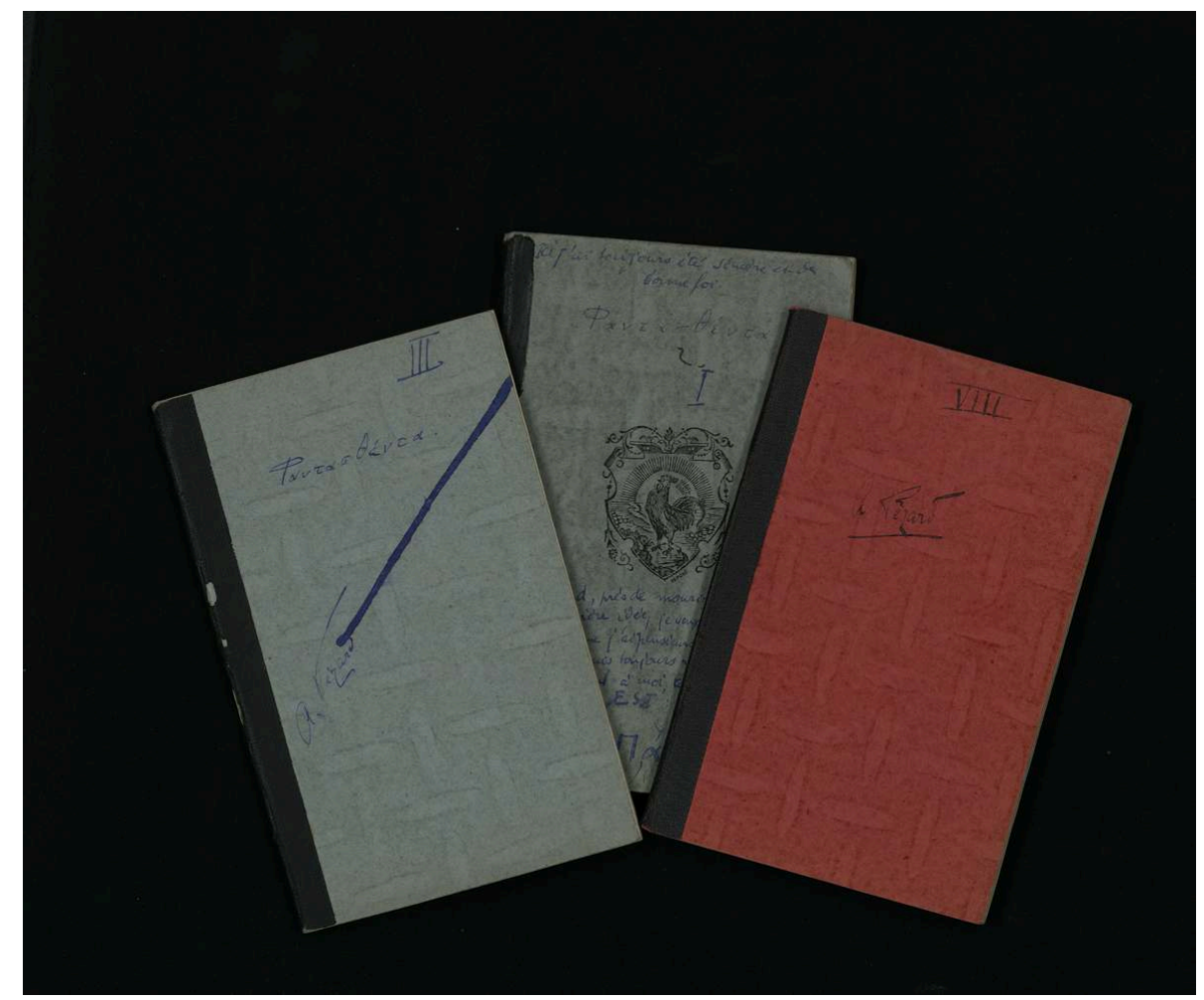

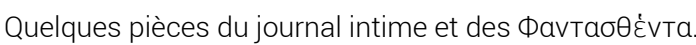

(c) Archives nationales.

9 Chez le jeune Pézard, initiation à l'écriture, à la poésie, à la réflexion, et exaltation des vertus viriles, patriotiques et guerrières constituent deux expériences concomitantes, marquant les années de jeunesse, de 1909 à 1914 (fig. 1). C'est en cela notamment que les nombreux journaux soigneusement conservés dans le fonds pour cette période offrent un éclairage précieux sur l'état d'esprit d'un jeune intellectuel parisien à la veille du premier conflit mondial (fig. 2). 
Figure 2

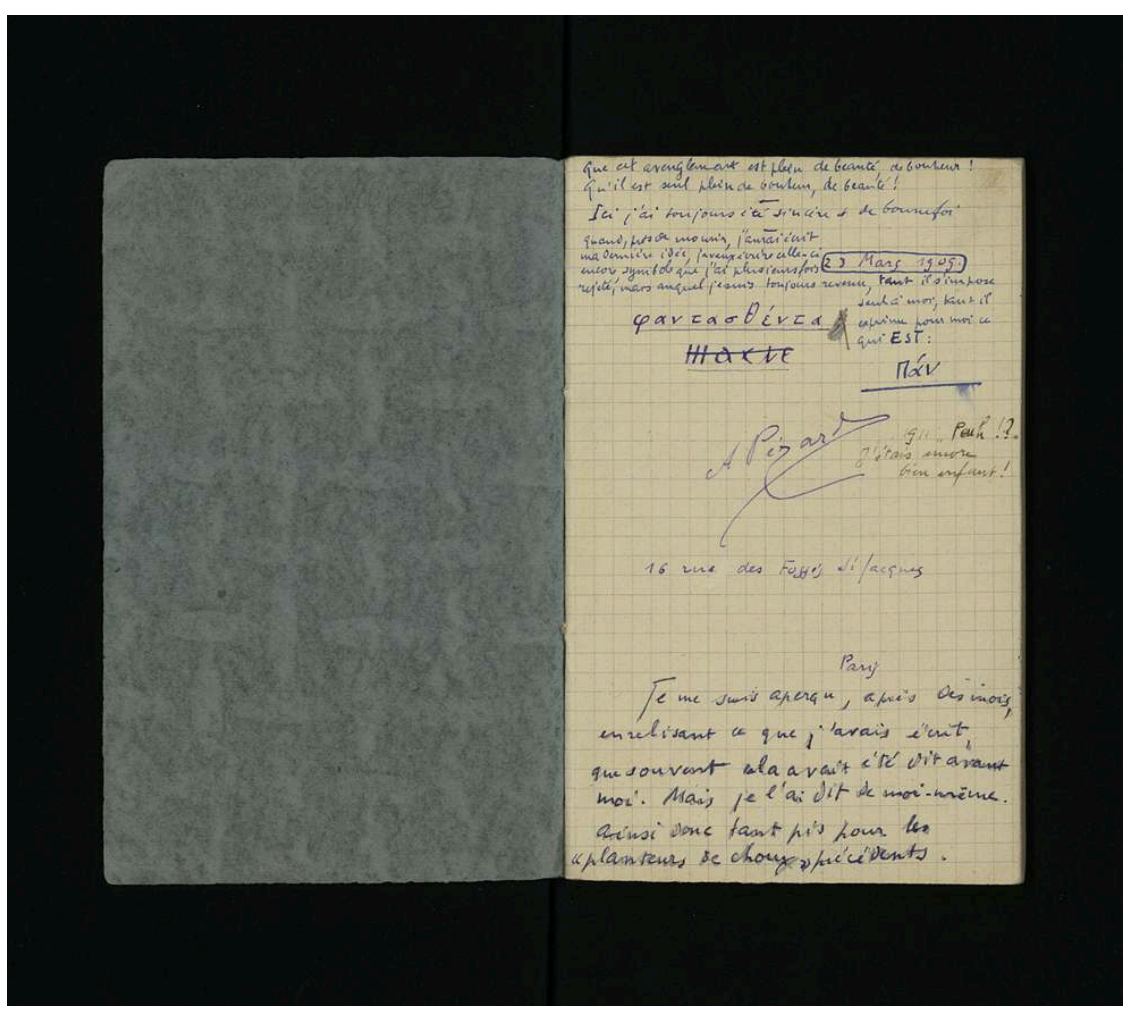

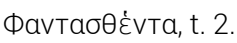

(c) Archives nationales.

10 Le journal intime proprement dit est tenu sur des petits carnets de couleur rouge, portant une numérotation (ajoutée à la main) en chiffres romains. D'autres, de même format et de même façon, mais de couleurs diverses (bleus et gris-verts), intitulés $\Phi \alpha \nu \tau \alpha \sigma \theta \dot{\varepsilon} \nu \tau \alpha$ (Arch. nat., $691 \mathrm{AP} / 4$, pièces 1-8), recueillent les pensées et les réflexions de nature philosophique et spirituelle d'André Pézard. Sa formation intellectuelle, ses lectures y apparaissent au grand jour. Ce sont celles d'un jeune lycéen doué,

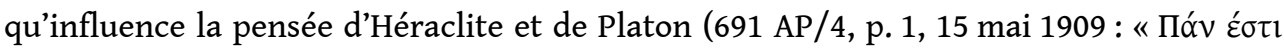

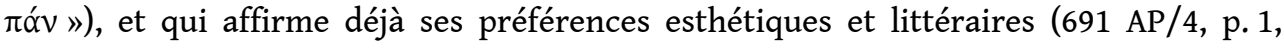
janvier 1910 sur le beau et le grand chez Eschyle, Dante...). En août 1910, Pézard découvre Nietzsche dont la forme volontiers aphoristique et les aspirations au Grand et au Beau trouvent chez lui un puissant écho :

8. Holleaux qui finit les vacances avec moi chez Funell m'a parlé de Nietzsche; je viens de m'apercevoir que souvent, là où je croyais être original, j'avais été précédé. Tant pis! חóv. Je ferai une poésie symbolique de la Cigale. / 9. Nietzsche est un grand tigre joyeux à la vue d'un bon déjeuner. (691 AP/4, p. 4) 
Figure 3

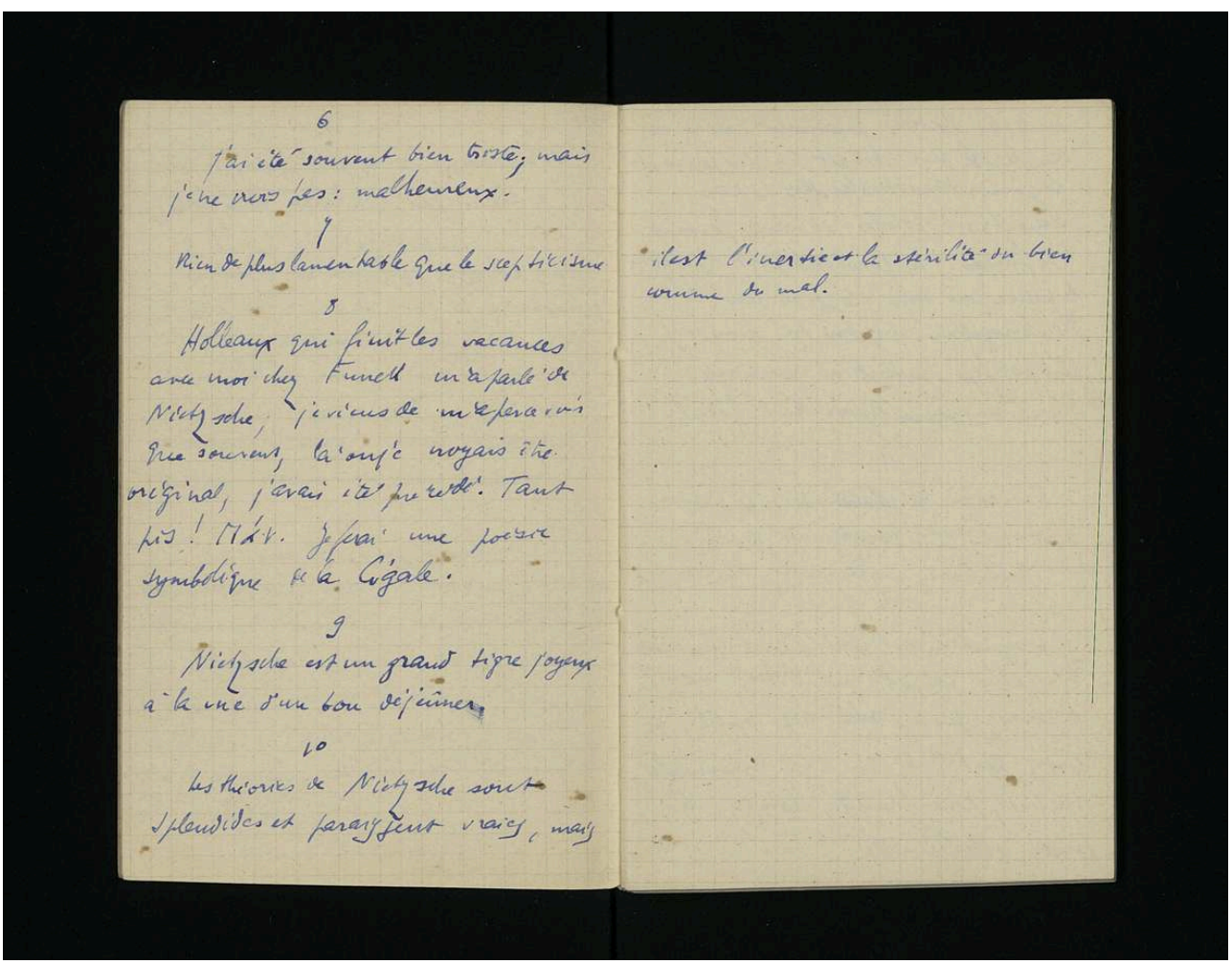

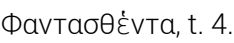

(c) Archives nationales.

11 À l'instar du philosophe en effet, le jeune homme, pétri, comme toute une génération, de propagande anti-allemande, exècre la pompe impériale des Prussiens et considère que "L'état de guerre développe toutes les facultés; l'état de guerre développe toutes les qualités viriles » (691 AP/4, p. 3, 29 juin 1910) (fig. 3). Il appelle la poésie même à se " muscler " aux grands modèles classiques, assimilables à "l'action", qui selon lui manque aux modernes (691 AP/4, p. 3, septembre 1910) (fig. 4). 
Figure 4

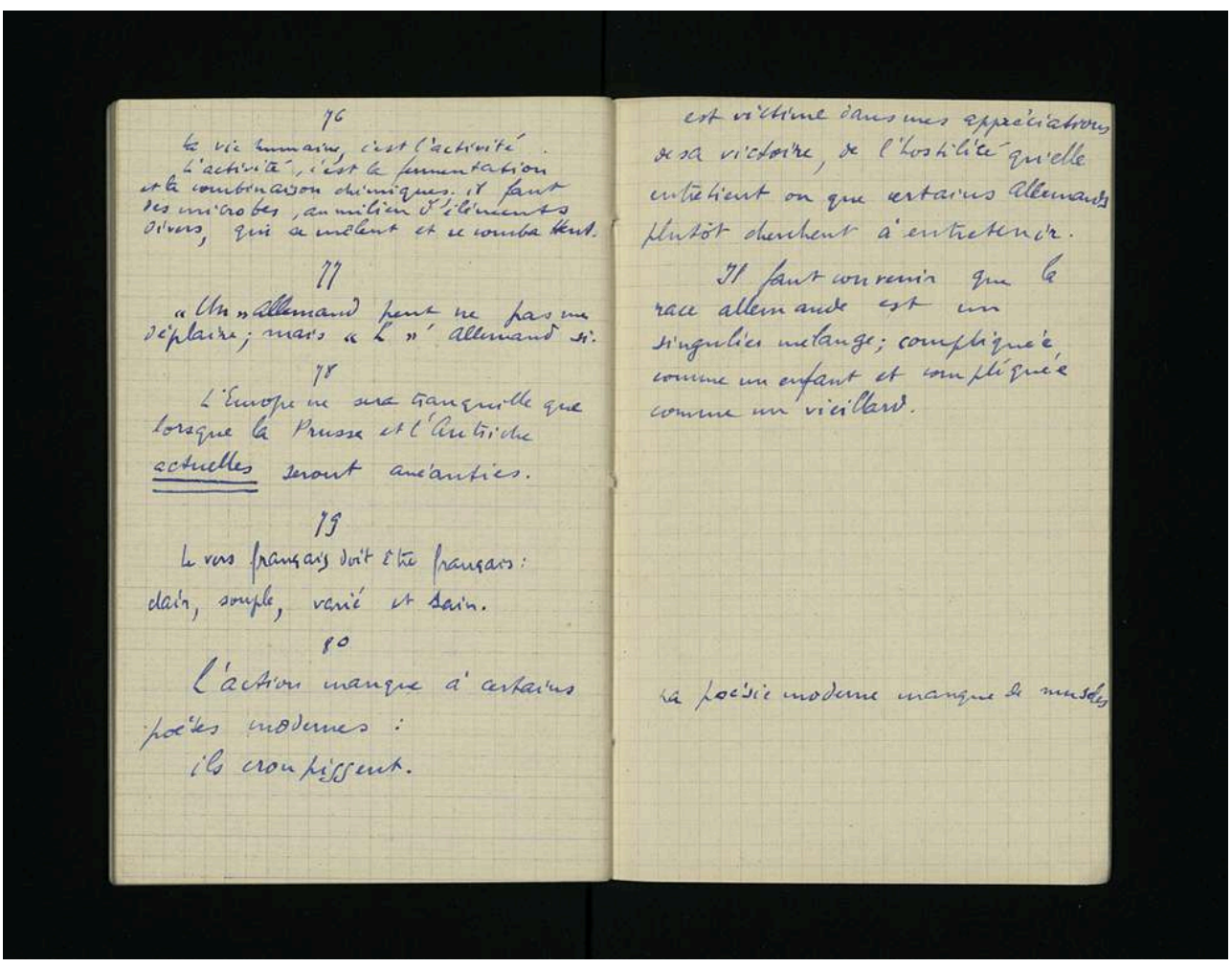

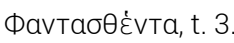

(c) Archives nationales.

12 Concernant cette guerre à laquelle il aspire comme à un grand ressourcement national et personnel, le lecteur d'Homère, d'Eschyle, de Dante, de Nietzsche a le sentiment cependant qu'elle sera nouvelle et singulière. Il concède, ainsi, dans un des $\Phi \alpha \nu \tau \alpha \sigma \theta \dot{\varepsilon} v \tau \alpha$ de janvier 1911 :

89. Entraîné par mon propre mouvement, j'ai eu tort de faire de plus en plus l'éloge systématique de la guerre (pour protester contre trop de veulerie et d'amour des jouissances). C'était bon autrefois, mais la guerre de demain ne sera plus les guerres d'autrefois.... (691 AP/4, p. 4)

Et l'auteur de ces lignes prémonitoires d'ajouter, quelques mois plus tard: "Si LA guerre éclatait, j'aurais le trac, mais j'irais » (691 AP/4, p. 5).

C'est dans cet état d'esprit que le khâgneux, tout fraîchement couronné des lauriers du concours d'entrée de la rue d'Ulm, fait part dans son journal intime (les carnets rouges précédemment cités) de son peu d'enthousiasme à l'annonce des résultats (691 AP/4, p. 16, samedi 24 juillet 1914) et de l'entrain qu'il tente de dissimuler à sa famille à l'idée d'une entrée en guerre imminente :

«On parle de la guerre; mon oncle a de mauvaises nouvelles. Je tâche de calmer et de montrer de l'entrain - et d'en cacher, car j'en ai trop - on me prendrait pour un vandale » (691 AP/4, p. 16, jeudi 29 juillet 1914). 
Figure 5

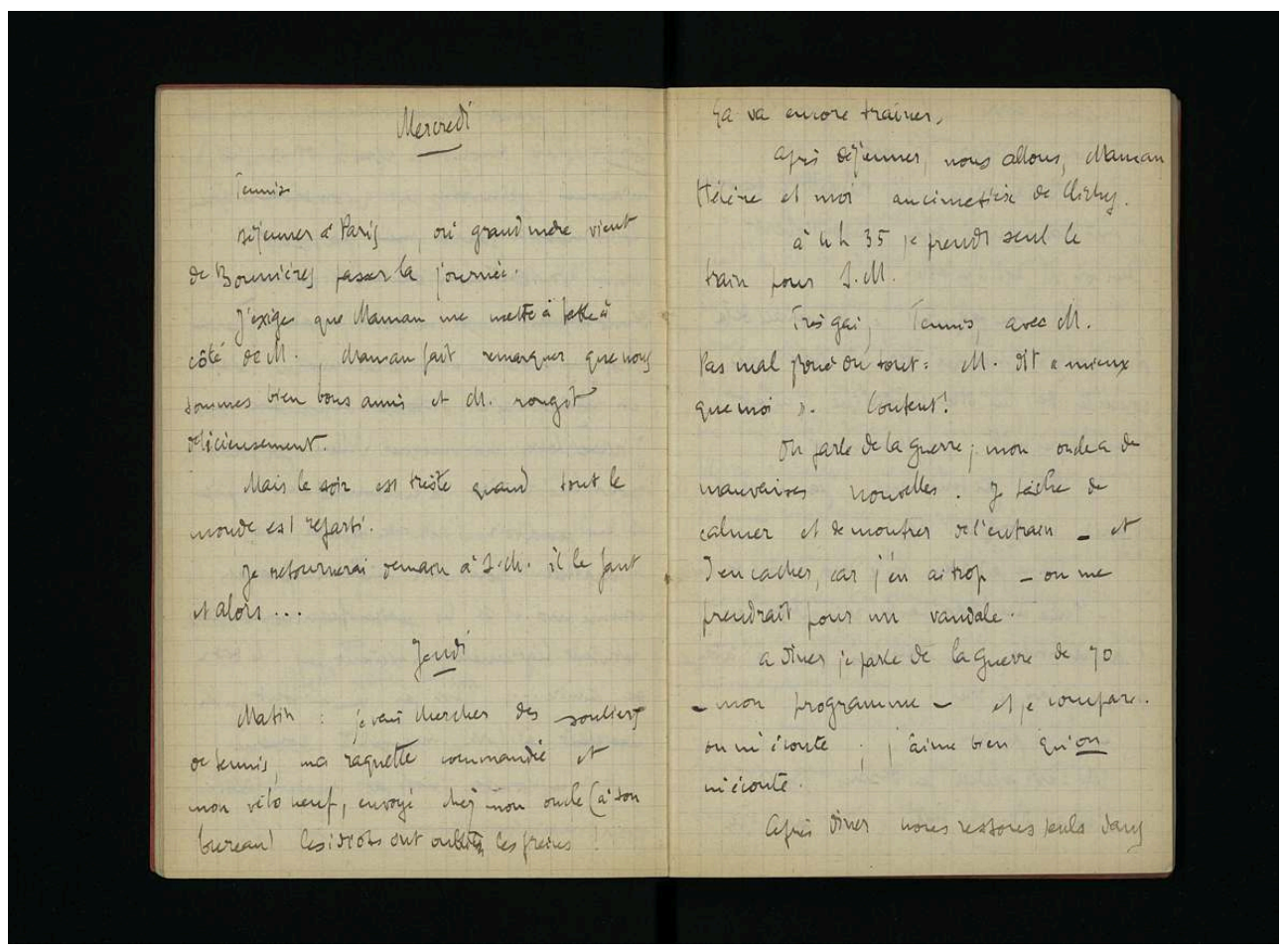

Journal intime, t. 8

(c) Archives nationales

Dans l'esprit de Pézard, la guerre à venir semble contenir l'espoir d'un rattrapage, celui des deux années de jeunesse perdues à la préparation du concours (691 AP/4, p. 16, samedi 24 juillet 1914) (fig. 5).

Ce journal « civil » s'interrompt en cette fin du mois de juillet 1914. Pézard le reprend du 6 décembre 1914 au 17 janvier 1915, période correspondant à son retour des classes à Mamers, pour l'abandonner à nouveau jusqu'au... 23 février 1917. Entre temps, il inaugure deux nouvelles séries que matérialisent là encore deux types distincts de calepins.

Le journal de guerre et les carnets militaires, comme point de départ 
Figure 6

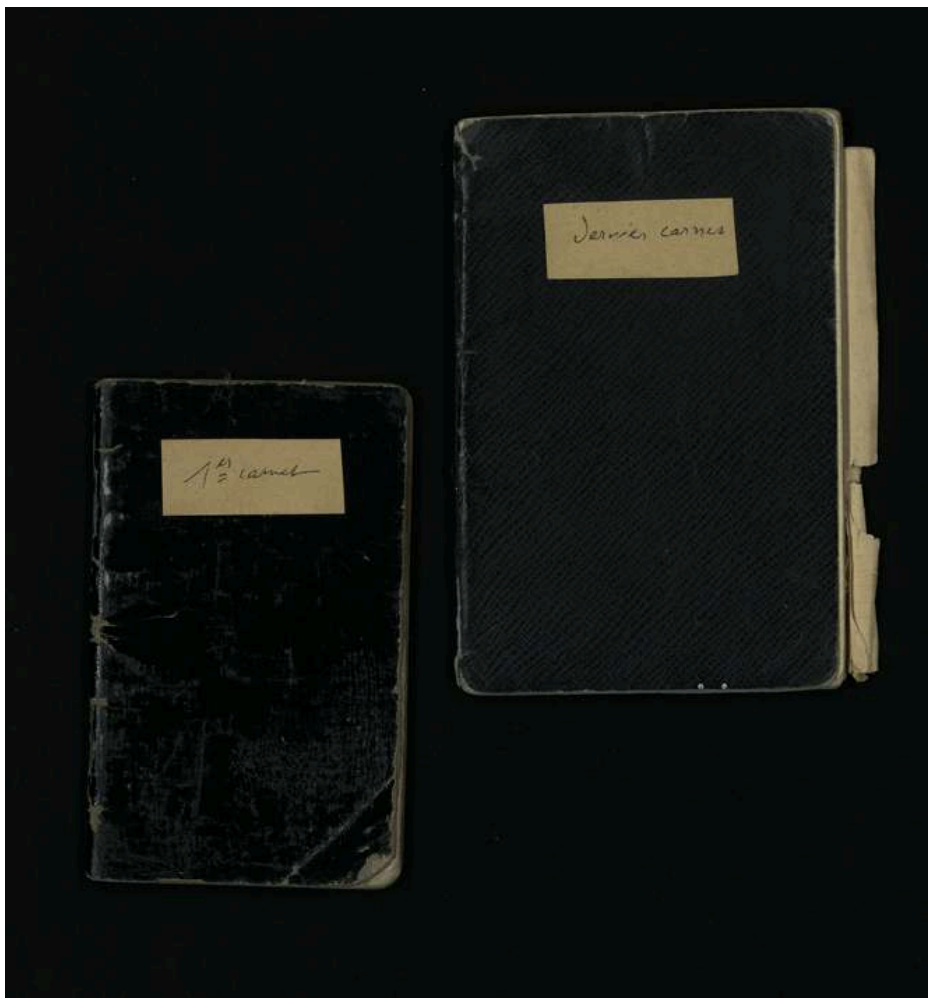

Carnets militaires.

(c) Archives nationales

\section{Figure 7}

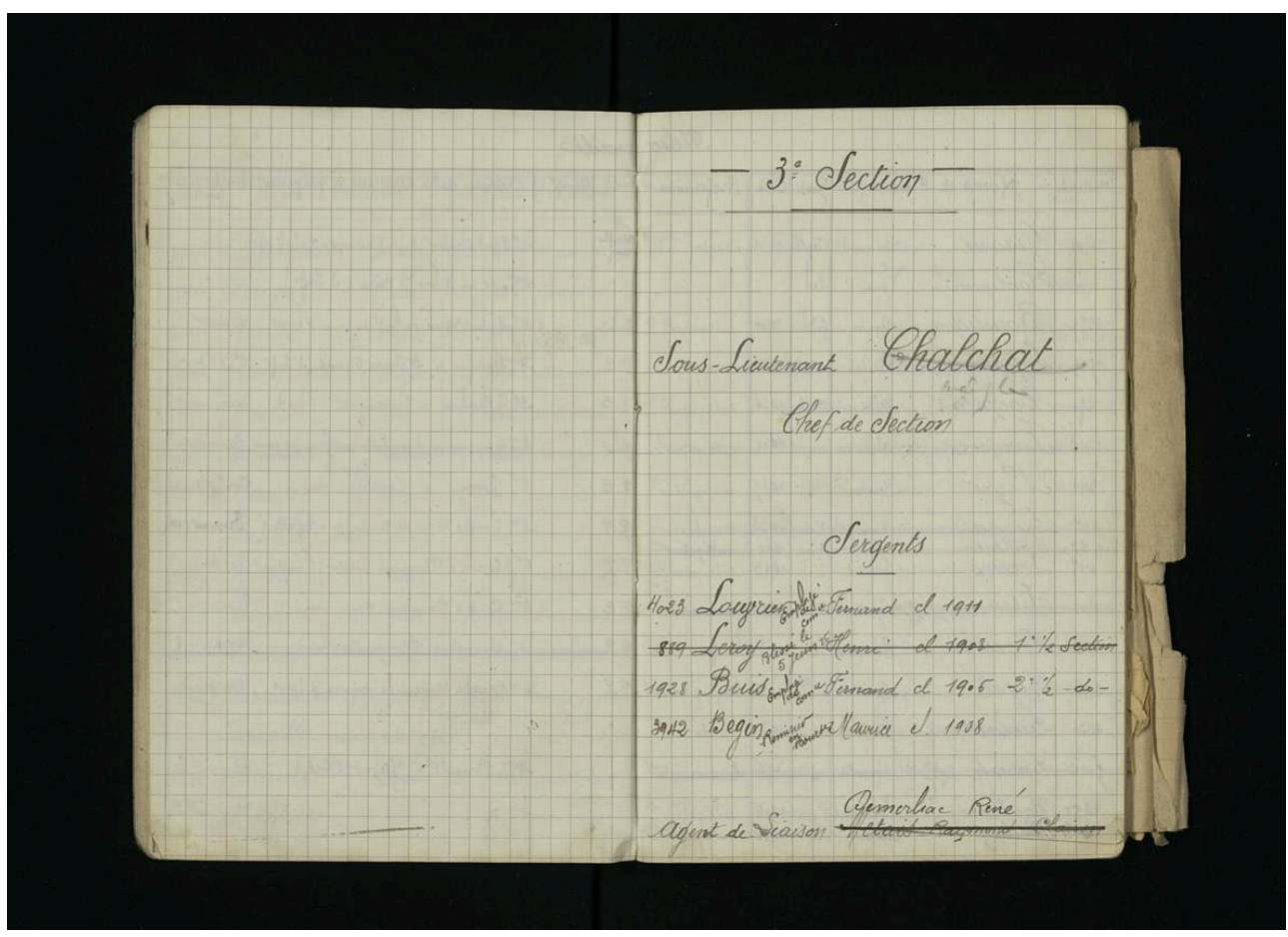

Dernier carnet militaire portant mention, biffée a posteriori (1917 ?) du sous-lieutenant Chalchat. (c) Archives nationales. 
Distinct des carnets militaires (691 AP/4, p. 19-25), qui consignent, après les instructions reçues durant les classes à Mamers, à partir d'octobre 1914 (691 AP/4, p.19), des informations concernant pour l'essentiel la composition des troupes auxquelles commande l'officier Pézard, le journal de guerre commence au $1^{\mathrm{er}}$ août 1914 (691 AP/4, p. 26) (fig. 6, 7). Il comporte sur ses deux gardes supérieures les grades et les régiments où le jeune officier sert successivement (états rayés, comme pour une mise à jour, jusqu'au 25-26 janvier 1915). Manifestement justifié par la nouvelle de la mobilisation générale, le choix d'un support nouveau, distinct des journaux antérieurs, s'impose si brutalement à Pézard qu'il note ses impressions des premiers jours sur des feuilles volantes, qu'il recopiera plus tard sur un nouveau carnet. En témoigne la mention portée en haut de la première page de ce premier tome du journal de guerre :

«Le commencement du mois d'août est sur 27 feuilles volantes que je recopierai textuellement en rentrant » (691 AP/4, p. 26, page correspondant au $1^{\mathrm{er}}$ août 1914).

Figure 8

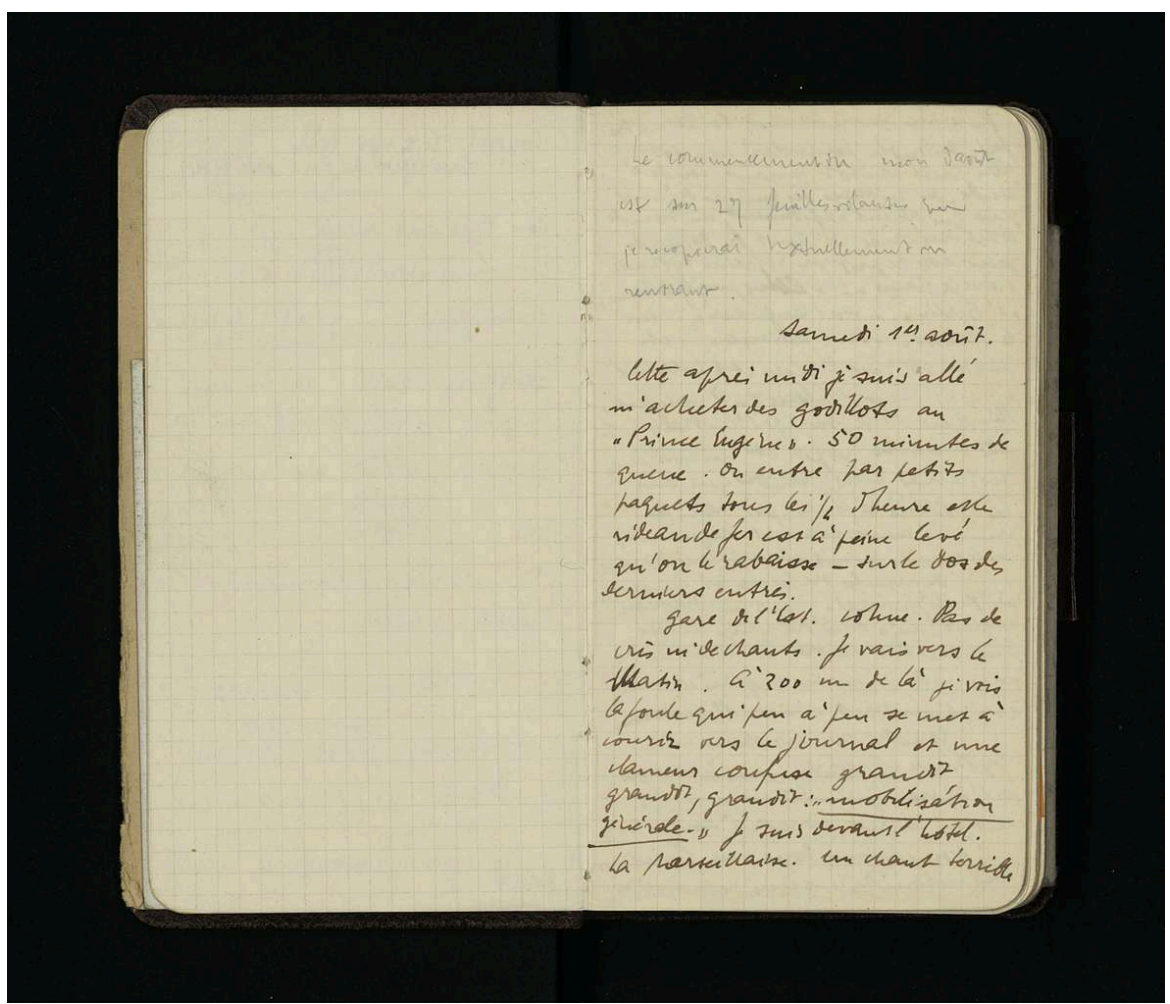

Journal de guerre, t. 1 .

(c) Archives nationales

Jusqu'à la date du 10 août en effet, veille du départ pour les classes à Mamers, l'écriture est soignée, posée, à l'encre (fig. 8). Elle se fait plus petite, car " prise sur le vif » et gênée manifestement par les conditions dans lesquelles elle est portée sur le carnet, à partir du 11 août. Entre ces deux « couches » distinctes de copie, une mention témoigne de la reprise a posteriori de ces pages par leur auteur, alors loin du front : «J'ai plusieurs fois souri en recopiant ces notes d'août 1914. Je regrette de m'être permis cela maintenant. Adieu !... »(691 AP/4, p. 26, lundi 16 avril 1917).

Pézard est coutumier de ces retours à la fois réflexifs, critiques et nostalgiques à ses écrits antérieurs - comme en témoignent les commentaires ex post qui déjà figuraient 
sur les $\Phi \alpha v \tau \alpha \sigma \theta \dot{\varepsilon} v \tau \alpha$ de jeunesse. Dans ces premières pages d'août 1914, il appelle en quelque sorte la lecture et le jugement qu'il portera plus tard sur ses propres mots :

«Oh Mamers! Commencer aller là, je ne me consolerai jamais d'avoir à l'avouer plus tard » (691 AP/4, p. 26, dimanche 9 août 1914).

Cette figure d'anticipation, prolepse à laquelle répond, à la page suivante, le commentaire précédemment cité en date du 16 avril 1917, témoigne d'une élaboration narrative préalable à la rédaction du journal. C'est là l'œuvre, déjà, d'un auteur conscient de la différence que comporte nativement l'écrit intime fait pour être relu mais surtout pour prendre sens au gré de reprises, d'usages ultérieurs ... Il en use de manière toujours raisonnée, comme en témoigne le soin qu'il apporte à distinguer, varier les supports, et à assurer la compréhension future, exhaustive, des archives qu'il constitue.

\section{Typologies $^{5}$}

Pézard est assurément conscient du potentiel à la fois littéraire et documentaire des témoignages qu'il consigne dans ses divers carnets: c'est ce qui motive aussi, très certainement, le soin méticuleux qu'il attache à préserver entre eux des distinctions typologiques strictes. À des fonctions différenciées d'écriture, au changement de statut du scripteur lui-même correspond le passage d'un type de carnet à un autre. Ainsi un premier changement matérialise, on l'a vu, l'interruption de la vie civile, l'entrée dans la vie militaire, dans le temps et le vécu frontal de la guerre (de $691 \mathrm{AP} / 4$, de la p. 16 à la p. 26). Dès avant la guerre, au reste, on l'a vu, Pézard distinguait scrupuleusement ses journaux intimes (carnets rouges), des carnets $\Phi \alpha v \tau \alpha \sigma \sigma \theta \dot{\varepsilon} v \tau \alpha$, à caractère philosophicopolitique. Les carnets de l'époque de la Grande Guerre témoignent de distinctions comparables. Le " journal civil », déserté en 1914, est néanmoins repris en 1917, lorsque le jeune officier blessé à la jambe et réformé est de retour à l'arrière, à Paris (691 AP/4, p. 16). La détestation de ce nouvel état, la nostalgie du front, en même temps que le dégoût de lui-même, de sa blessure et la honte de ne plus être parmi ses hommes inspirent les lignes qu'il écrit le 23 février 1917 : « Boiteux est allé à Clermont-de-l'Oise voir le Dr Collard, avec un dernier et vague espoir qu'on pouvait encore faire quelque chose pour sa patte » $(691 \mathrm{AP} / 4, \mathrm{p} .16)$. 
Figure 9

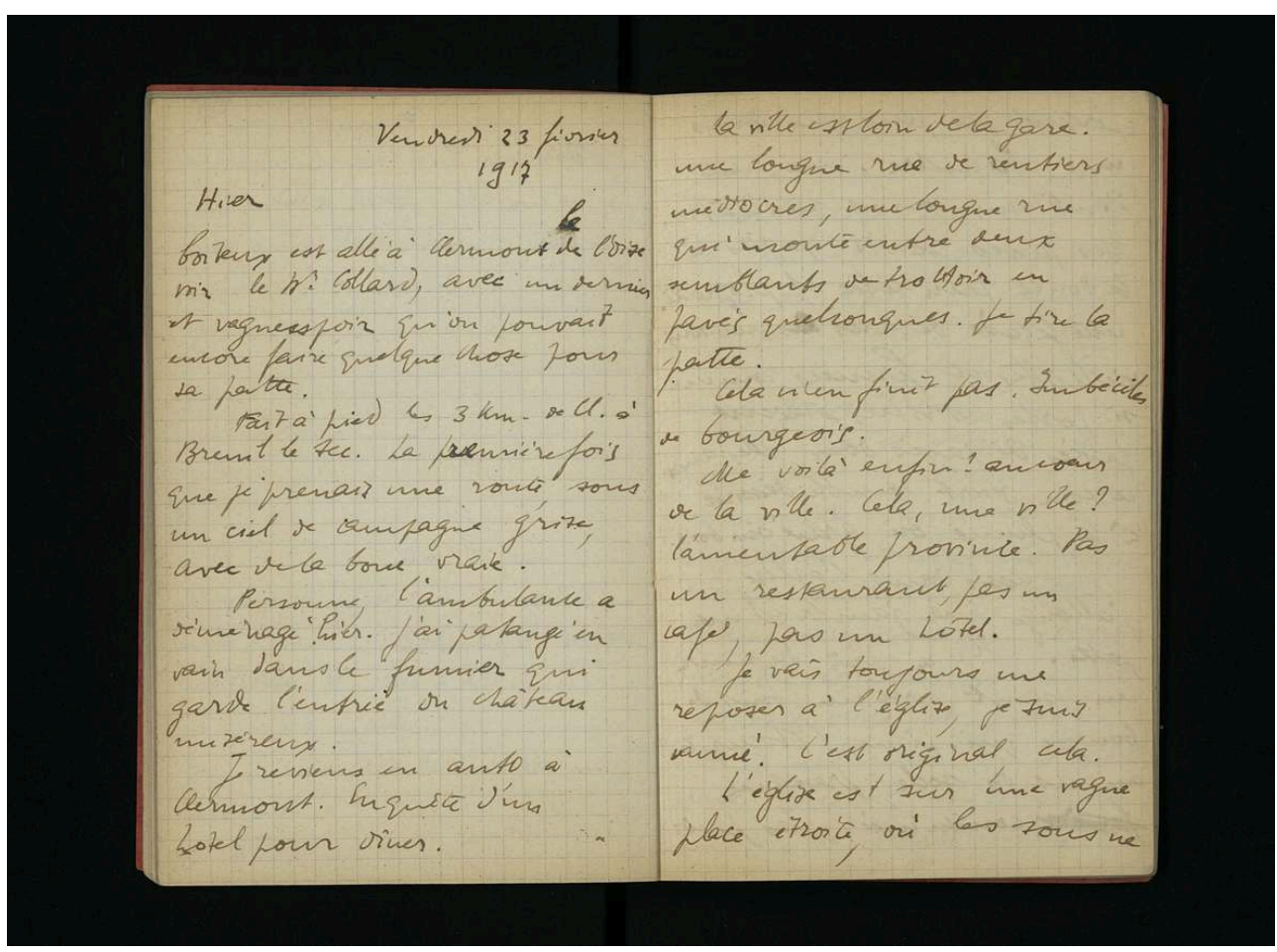

Journal intime, t. 8.

(c) Archives nationales.

22 Revenu à la vie loin du front, Pézard change de carnet comme il change d'habit : inapte à l'uniforme, il ne s'estime plus digne de consigner ses pensées dans son journal de guerre (fig. 9).

De cette typologie intellectuelle strictement définie dépendent des choix de présentation matérielle. De même, en effet, que $\Phi \alpha v \tau \alpha \sigma \theta \dot{\varepsilon} v \tau \alpha$ et journaux intimes appelaient des carnets de couleurs différentes (quoique de la même marque), carnets militaires et journaux intimes se distinguent, de prime abord, en ce que les premiers sont uniformément recouverts d'une sorte de toile cirée noire, éventuellement étiquetée a posteriori (voir $691 \mathrm{AP} / 4$, p. 19 et p. 24, "premier carnet » et "dernier carnet»). Les journaux, eux, souffrent plus de variété matérielle, mais ont tous néanmoins en commun, outre leur format oblong, leur dos carré et leur couvrure plus robuste que celle des carnets précédents.

24 C'est que Pézard porte un intérêt et un soin manifeste au choix de ses supports d'écriture. Ainsi note-t-il à la dernière page du second tome de son journal de guerre (18 mars 1915-7 septembre 1915) : «J'avais acheté ce carnet à la fin de 1911 pour n'avoir qu'à le mettre dans ma poche le jour où la guerre éclaterait. Je ne l'ai (je n'ai ?) employé que le $2^{\mathrm{e}}$ parce que l'autre, donné par Grand-mère, portait un crayon et fermait par un élastique, plus pratique à la guerre » (691 AP/4, p. 27).

25 Le «carnet au crayon " dont il est question constitue en effet le premier tome du journal (1 ${ }^{\text {er }}$ août 1914-18 mars 1915 : 691 AP/4, p. 26) (fig. 10). 
Figure 10

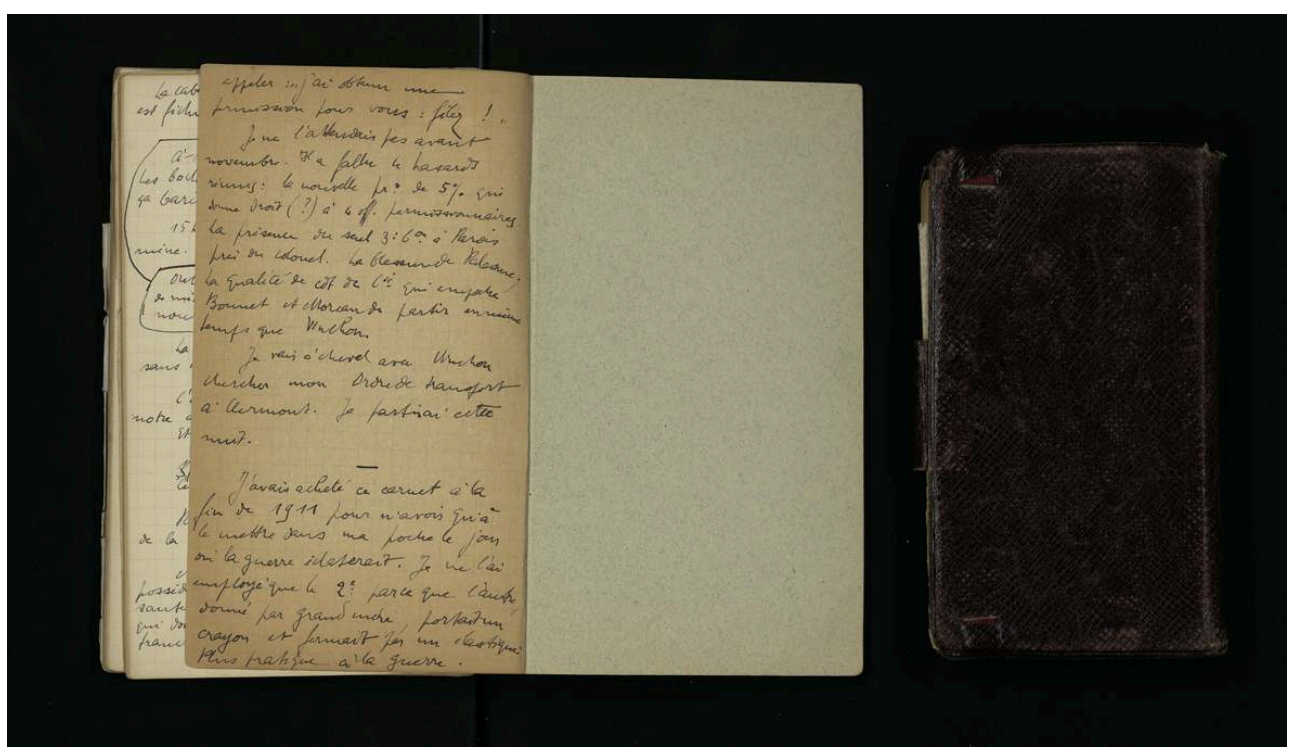

Journal de guerre, t. 1 et 2 .

(c) Archives nationales.

À mesure qu'il constitue cette documentation, Pézard a soin d'en tenir un plan raisonné, d'y multiplier les clefs qui en permettront l'accès lors de consultations ultérieures. En témoigne l'organisation sans faille qu'il met en œuvre, sous forme d'une série de renvois internes liant les différents documents qu'il produit, et figurant une forme de plan de classement du matériau en devenir.

\section{Constituer l'archive}

27 Étranges à première vue, des mentions chiffrées ajoutées à la main dans les journaux de guerre font référence aux lettres envoyées par André à sa famille ainsi qu'aux photographies qu'il réalise au moyen de son appareil photographique.

Les lettres à sa sœur Hélène ${ }^{6}$ constituent d'emblée pour Pézard un lieu d'écriture privilégié. Qu'il ait anticipé une disparition - de lui-même, de ses carnets - ou qu'il ait souhaité développer sur un autre mode, épistolaire, tenant de l'adresse directe à un interlocuteur bien réel, les propos consignés dans son journal, ces envois sont jugés suffisamment importants, éclairants, pour comporter une numérotation reportée sur le carnet au moment de l'envoi.

Il ne peut s'agir d'un simple compte du courrier reçu et envoyé. Dans ses lettres ou ses cartes, dont certaines comportaient manifestement du texte caché, copié à l'encre sympathique, Pézard, pour emprunter au vocabulaire de la photographie, qu'il pratique, change de focale : au quotidien des tranchées vient se surimposer l'attention renouvelée du soldat au contexte général, politique, de la guerre et du temps, à la situation géopolitique de l'Europe belligérante, sorte de diversion qu'il opère non seulement pour distraire ses proches - et lui-même - d'une tension, d'une angoisse incessantes, mais aussi, peut-être, pour consigner en un autre lieu, complémentaire et réservé, ce type d'observations : il lui sera ainsi loisible, plus tard, de replacer chaque élément du puzzle dans une chronologie personnelle complète. 
30 L'«indexation» des prises de vue réalisées au moyen de son appareil photo - un vestpocket que Pézard se fait offrir par son père pour " photographier la guerre » répond avant tout à des nécessités d'ordre pratique. La lettre grecque $\varphi$ précède l'introduction d'«index photographiques». À chaque pellicule entamée correspond une lettre grecque ou latine distincte, que suivent des numéros correspondant aux sujets photographiés, dans l'ordre de prise de vue : lieux, personnes ... Ces mentions permettent, a posteriori, de comprendre et de reconnaître le moment, la chronologie, le contexte, les sujets mêmes (fig. 11, 12).

Figure 11

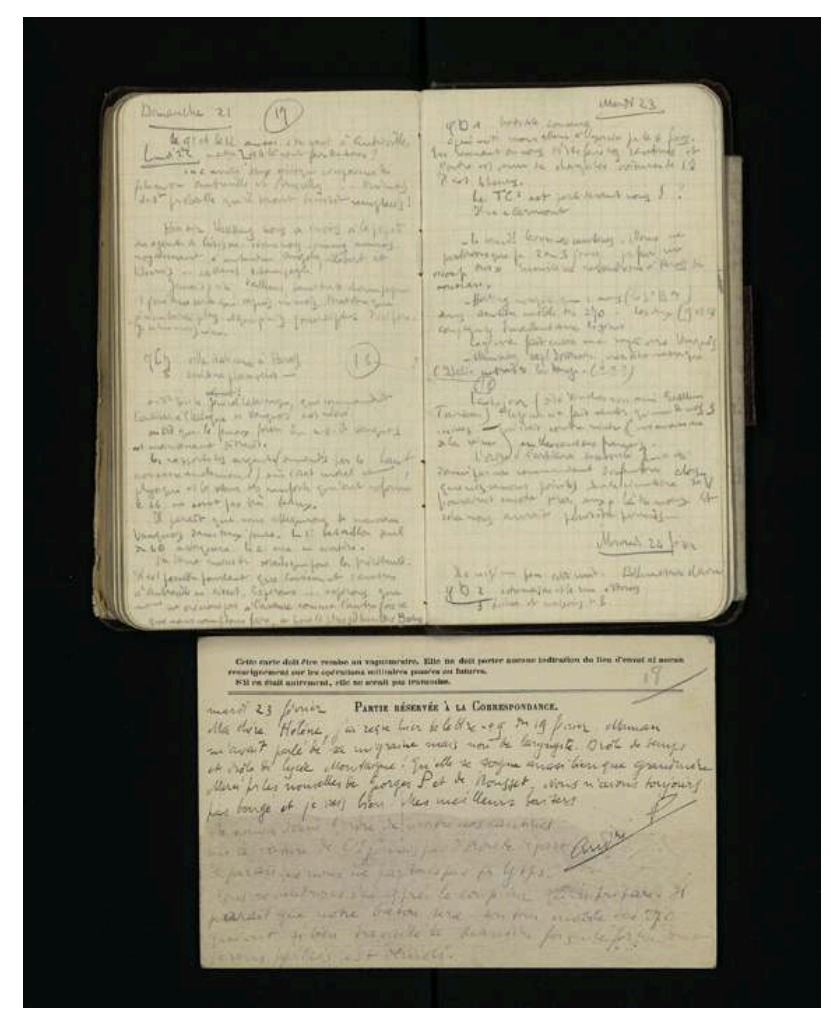

Journal de guerre, t. 1 et carte à Hélène, comportant la numérotation correspondant à celle du carnet. Traces d'usage, sur la carte, d'un révélateur d'encre sympathique. Le carnet introduit en outre par la lettre grecque $\varphi$ un recensement de clichés photographiques réalisés par Pézard, et ici décrits.

(C) Archives nationales. 
Figure 12

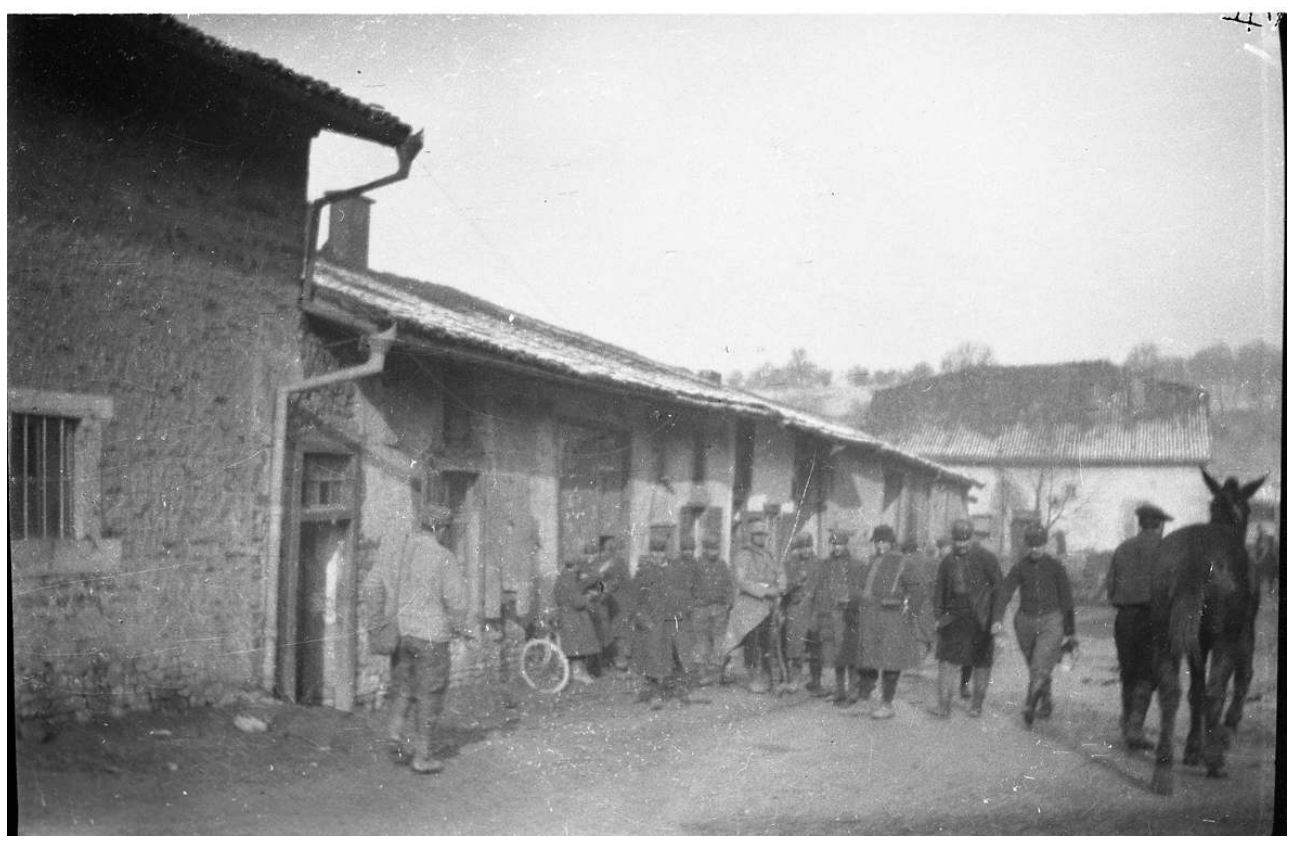

Cliché réalisé par André Pézard et correspondant à la mention portée sur la page de droite du carnet (en bas de page, voir Photo 11), à la date du 24 février <1915>: « $\varphi$ D2 Notre maison et la rue à Parois ».

Phot. Lejeune, Bernard. (c) Archives nationales

31 L'objectif est très clairement là d'associer textes, descriptions, récits et images collectés sur le vif et renseignant, chacun de son point de vue, comme un faisceau d'indices, une même situation, un même événement vécus. Au-delà d'un besoin immédiat de témoigner, de consigner la mémoire d'une expérience, ces pratiques dénotent une autre ambition: rendre accessible après coup la consultation et l'utilisation d'un matériau le mieux informé possible.

\section{Le temps retrouvé}

Il s'agit en outre d'un matériau vivant, susceptible de recevoir les traces tangibles qui témoignent de la vocation assignée par Pézard aux archives qu'il produit: porter la mémoire, dans un avenir proche ou lointain, de son expérience de soldat. Ainsi le journal de guerre comporte-t-il plusieurs couches d'intervention manuscrite, étalées dans le temps.

De même en effet que le journal intime « civil » est repris « à l'arrière », lorsque Pézard convalescent est rapatrié loin du front, de même le cinquième et dernier tome du journal de guerre (5-7 juin 1916-13 décembre 1916) recueille, des années plus tard, des mentions nouvelles. Consignées à des décennies d'intervalle les unes des autres, elles ont en commun la figure du retour : retour du souvenir de la guerre, des compagnons d'armes : « 26 janvier 1917 Rey vient enfin me rejoindre

20 décembre 1939 Limonest. Brouillard glacé. Guerre

Paris. Rey vient de mourir à Verdun le 21 ou 22 décembre 1972 » (691 AP/4, p. 29). 
Figure 13

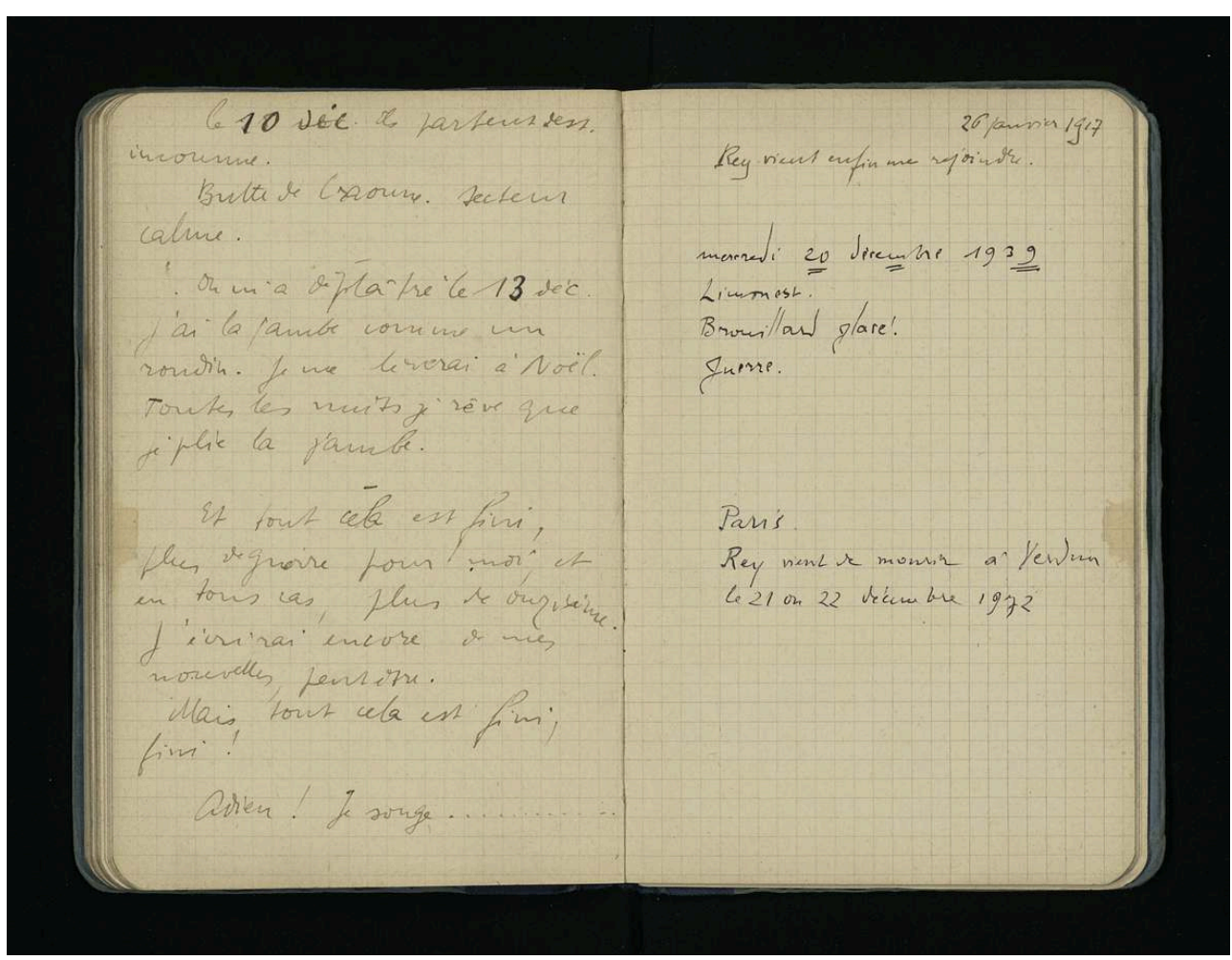

Journal de guerre, t. 5 .

(c) Archives nationales.

36 À la joie des retrouvailles avec Rey, survivant de Vauquois comme Pézard, succède, lapidaire, l'évocation quasi-spectrale de la guerre associée au «brouillard glacé » de décembre 1939 (fig. 13). Le journal s'achève, à la suite, avec la fin évoquée du dernier compagnon survivant - mort à Verdun, par une ironie que Pézard suggère sans plus la commenter.

37 L'épaisseur temporelle que gagne le journal se trouve en quelque sorte court-circuitée par cette ultime mention, qui boucle la boucle d'un cycle où, toujours, la guerre se trouve associée à la camaraderie, à l'amitié, «à mes amis qui sont morts ", comme l'indique la dédicace de Vauquois.

38 La conscience de vivre une expérience unique dont il importe de fixer le souvenir, le plus précisément possible - pour soi, et au-delà - tout autant que la nécessité d'exprimer ce que l'on ne saurait rapporter à ses proches eux-mêmes motive l'inlassable et très méthodique travail d'écriture que Pézard entreprend. Cette entreprise reste ouverte, en progression: les carnets «s'enrichissent» de mentions postérieures, d'une part, leur auteur reprend, à l'arrière, les notes, les preuves accumulées pour les recomposer sous une forme destinée à la publication, d'autre part. Les archives renseignent alors la transformation d'un matériau pris sur le vif en une matière littéraire, offrant des ressources inexplorées à la génétique textuelle. 


\section{La guerre comme matériau littéraire : archives et génétique des textes}

Dans les deux cas qui nous intéressent, le fonds conserve en effet les différents états du travail d'élaboration des textes publiés, voire les repentirs et les corrections que Pézard a l'habitude d'y apporter avant réédition.

\section{« La dernière relève »}

Il s'agit d'un court récit au caractère de parabole, de conte presque fantastique, publié pour la première fois dans le journal L'Horizon juste après l'armistice et intitulé « La dernière patrouille ». Il sera réédité, avec des corrections qui portent notamment sur le titre lui-même, le 7 septembre 1919 dans Le Matin.

41 Elle met en scène deux soldats après l'armistice, décidant de se rendre au front. C'est dans un boyau de « la butte » - référence manifeste à la butte de Vauquois, prémonition de ce que sera le premier chapitre de Nous autres à Vauquois -, qu'ils se trouvent confrontés à un "monstre symbolique et moribond", qui les ramène, comme un cauchemar, aux pires heures de la guerre, aux compagnons qui sont morts. Car cette sombre parabole a en réalité pour protagoniste principal «la bête ", évocation de la douleur, de la peine, de l'effroi des tranchées, que l'on tue après guerre pour en effacer le souvenir.

De ce texte subsistent dans le fonds les différents états: le manuscrit autographe annoté ; la première édition, dans L'Horizon. Journal des Poilus, $3^{\mathrm{e}}$ année, de « La dernière patrouille "; la coupure de L'Horizon annotée et corrigée de la main de Pézard en vue d'une réédition de la nouvelle, sous le titre "La dernière relève. Conte de l'armistice "; l'extrait du Matin du dimanche 7 septembre 1919 présentant le récit corrigé et sous son nouveau titre (691 AP 13) (fig. 14, 15). 
Figure 14

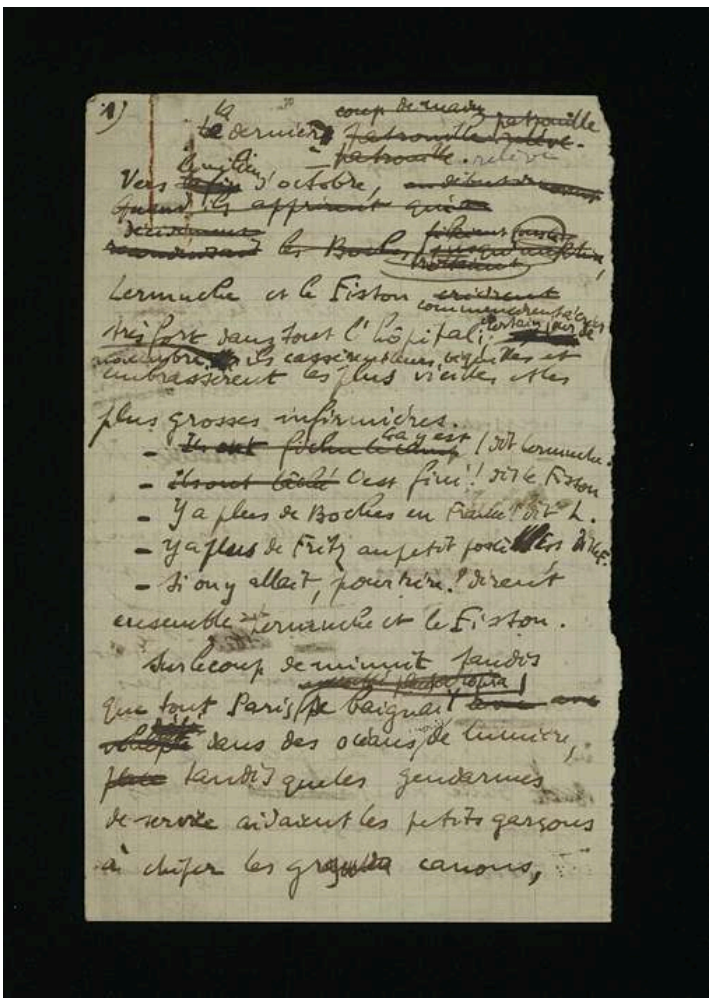

Brouillon manuscrit de "La dernière relève ».

(c) Archives nationales. 
Figure 15

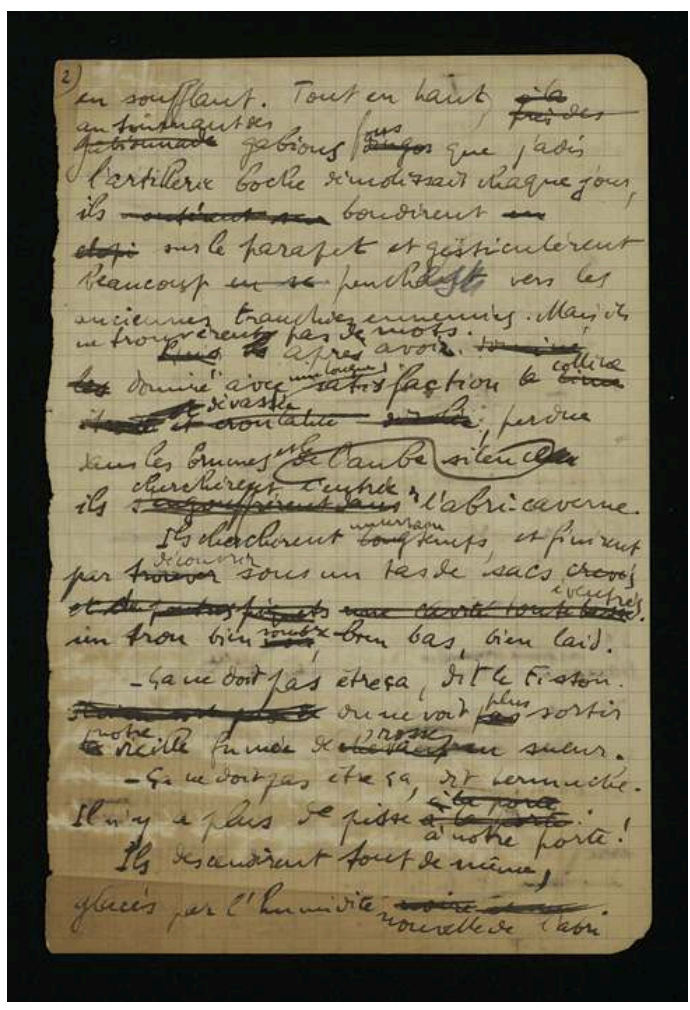

Brouillon manuscrit de « La dernière relève ».

(c) Archives nationales.

43 Les documents montrent que le titre de la nouvelle a en réalité changé deux fois. Un premier titre, "Le dernier coup de main », est biffé et remplacé dans le brouillon manuscrit par celui sous lequel L'Horizon publiera la nouvelle: «La dernière patrouille ». Le changement qui intervient d'une édition à l'autre est matérialisé par les corrections, à l'encre bleue, portées par Pézard sur l'extrait de L'Horizon, sans doute en 1919. Le nouveau titre, celui du Matin - « La dernière relève » - est, sans doute au même moment, reporté au crayon sur le brouillon manuscrit. 
Figure 16

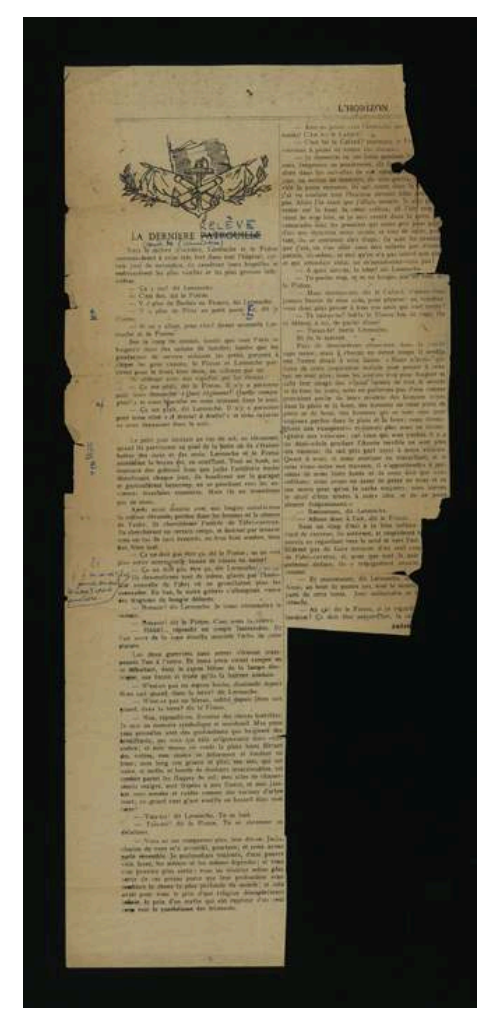

Extrait du journal L'Horizon corrigé.

(c) Archives nationales.

44 Ce dernier comporte en outre des passages «censurés » dans l'édition de L'Horizon puis rétablis in fine, non pas sous la forme portée à la main par Pézard sur l'extrait du journal, mais suivant le premier jet de son manuscrit original (fig. 16).

La variante porte sur un des échanges entre Le Fiston et Lermuche :

1- Manuscrit - «Ça ne doit pas être ça, dit Lermuche. Il n'y a plus de pisse [rayé à la porte] à notre porte. »

47 2- Nouvelle parue dans L'Horizon - «Ça ne doit pas être ça, dit Lermuche. »

48 3- Édition de L'Horizon annotée par Pézard - « Ça ne doit pas être ça, dit Lermuche ; on ne voit plus jaunir au seuil la mare d'urine familière (ajout manuscrit à l'encre bleue dans la marge) ».

4- Nouvelle parue dans Le Matin - « Ça ne doit pas être ça, dit Lermuche. Il n'y a plus de pisse à notre porte ».

50 L'ultime version publiée fait retour à la première version du texte, la plus triviale, la plus conforme aussi à l'économie de moyens qui caractérise Pézard et que l'on retrouve dans Vauquois.

51 « Ne voudrez-vous plus penser à vos amis qui sont morts » dira la bête du conte avant d'être tuée par les deux soldats. C'est à cette question que Pézard n'a de cesse de répondre. Nous autres à Vauquois lui en fournit l'occasion. 


\section{Le grand œuvre : Vauquois}

52 Il s'agit là d'une narration plus ample, assumant une posture résolument autobiographique et intradiégétique. La guerre y est décrite à hauteur d'homme, le récit laissant une large part à l'expression de sensations et d'observations qui en constituent le tissu poétique. Ce qui importe avant tout à Pézard, c'est de rendre compte de la vie - et de la mort - de son régiment, de ses hommes, ponctuant le récit de dialogues, mais aussi de transcriptions de chansons (textes et musique). Les adresses, au style direct, à Fairise mort en particulier, qui viennent interrompre le cours narratif, donnent tout son sens à la dédicace du livre « À mes amis qui sont morts ».

Fairise, Fairise, ils ne savent donc pas que tu es vraiment mort, eux tous qui parlent de toi maintenant? La fièvre prophétique de Roudsky nous a-t-elle tant désemparés, que nous avons l'âme plus tourmentée que triste en pensant à toi ? [...] $\mathrm{Tu}$ étais si vivant, Fairise, que la mort qui atteint les autres semblait ne pouvoir t'atteindre de même façon qu'eux. [...] C'est trop de paroles, Fairise ; nous t'aimions, mon ami, et voici tout simplement que l'on t'a tué dans cette forêt, d'où nous nous sommes évadés. (Nous autres à Vauquois, 1918, p. 49)

La guerre en effet, pour Pézard, lie les hommes indéfectiblement, noue des amitiés qui la font regretter. Un gouffre sépare cette écriture vibrante et sensible de la prise de notes rapide, heurtée, qui caractérise le journal de guerre.

De l'un à l'autre, les archives Pézard permettent de reconstituer le processus de reconstruction littéraire dont Vauquois est la phase ultime.

Trois grandes étapes trouvent leur matérialisation dans le fonds, que complètent les repentirs portés sur l'édition de 1918 en vue de la réédition de 1974.

1. Journal de guerre, tome 1, $691 \mathrm{AP} / 4$, p. 26

2. « Vauquois »: Genèse $(<1917>)^{7}, 691$ AP 13

3. Manuscrit de Vauquois, 691 AP 13

4. Copie annotée et corrigée à la main de la première édition en vue de la nouvelle édition de 1974, 691 AP 15. 
Figure 17

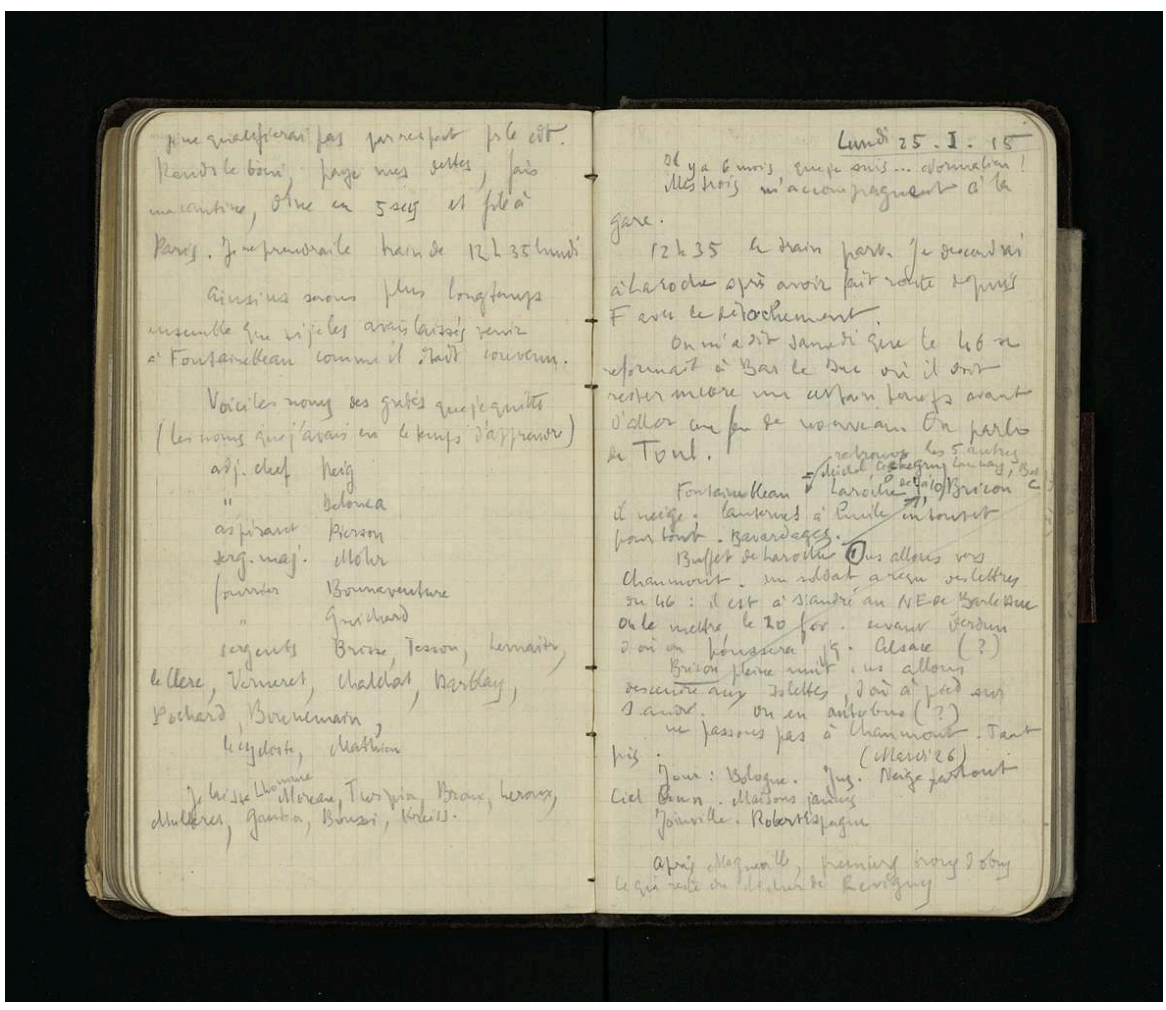

Journal de guerre, t. 1, 25 et 26 janvier 1915 .

(c) Archives nationales. 
Figure 18

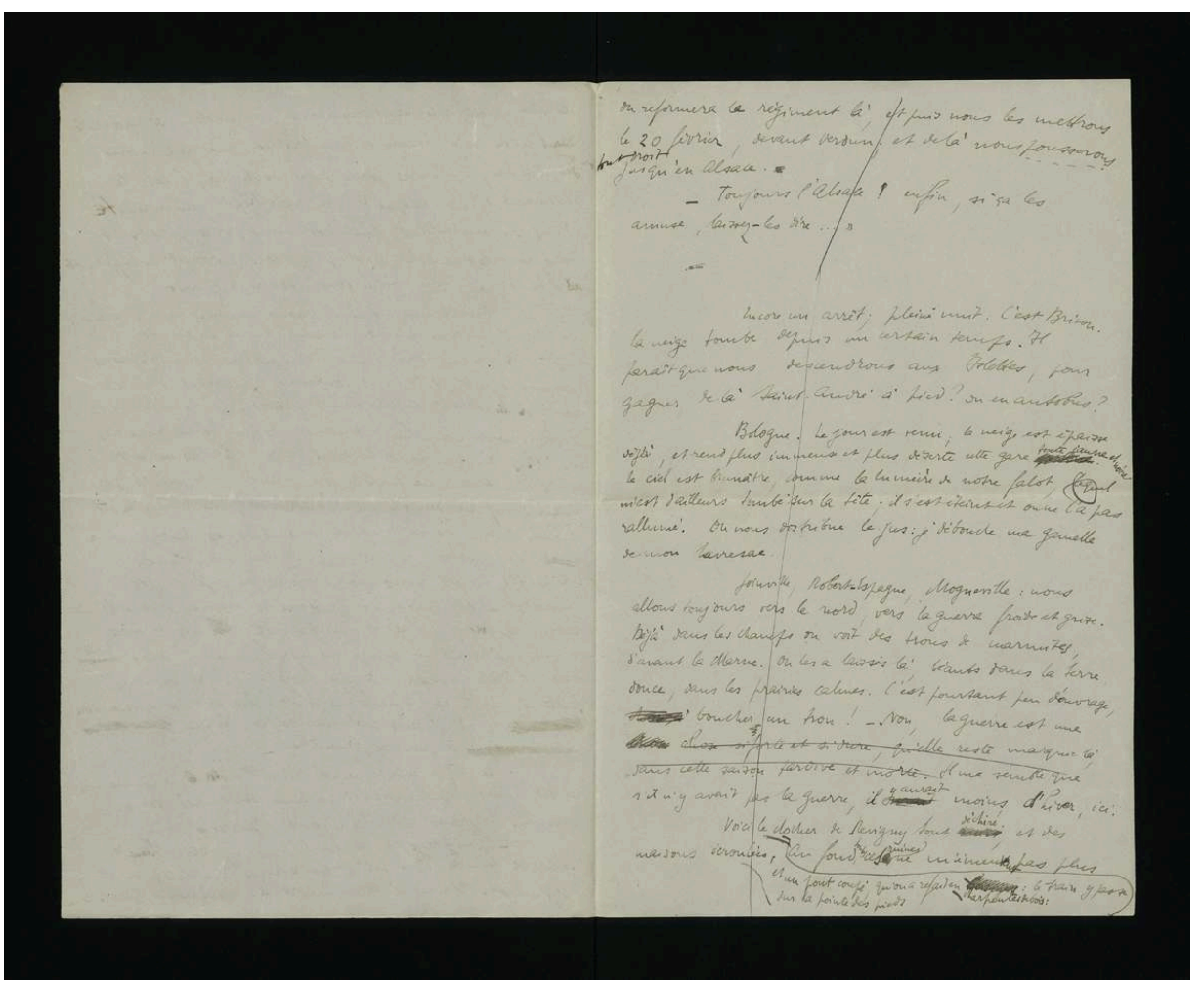

Brouillon manuscrit «Vauquois avant Vauquois ».

(c) Archives nationales. 
Figure 19

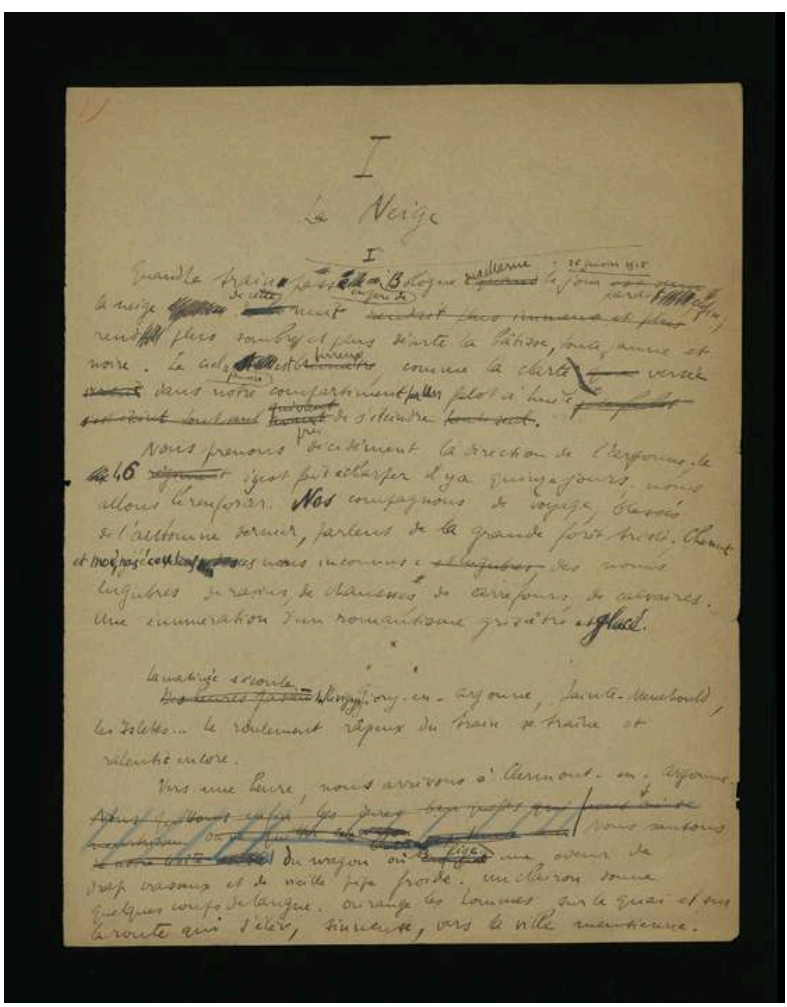

Manuscrit de Nous autres à Vauquois.

(c) Archives nationales. 
Figure 20

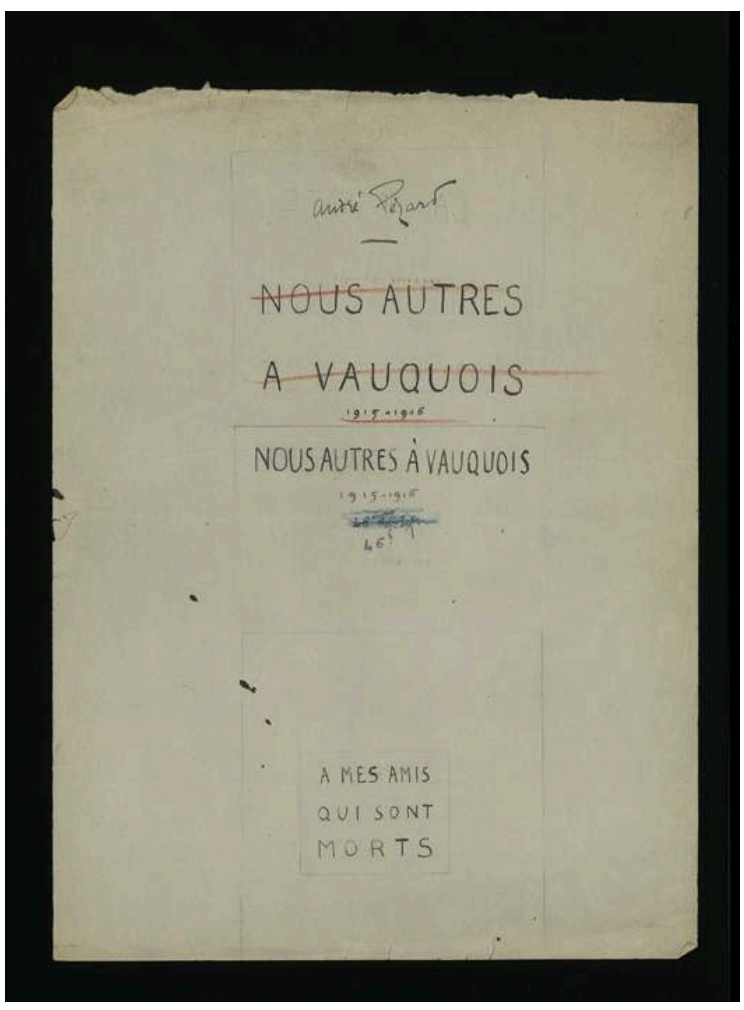

Essais de page de titre de Vauquois.

(c) Archives nationales.

\section{(fig. 17, 18, 19, 20)}

Un essai de génétique appliquée : 25-26 janvier 1914/La Butte. La Neige

Le tableau qui suit s'attache à décrire les évolutions entre les trois premiers états que l'on vient de mentionner, sur la base d'un court extrait, correspondant aux 25 et 26 janvier 1914 - soit au commencement du livre.

\begin{tabular}{l|l} 
1. Journal, tome I, & 2. Premier jet de réécriture :
\end{tabular} Exposé lapidaire et utilisation du matériau collecté dans factuel le journal

3. Le manuscrit de Vauquois avec ses repentirs 
« Lundi 25 I 15 (...)

Buffet de Laroche $^{8}(1)$.

Nous allons vers

Chaumont. Un soldat a reçu des lettres du 46: il est à SaintAndré au nord-est de Bar-le-Duc. On le mettra, le 20 février, avant Verdun d'où on le poussera jusqu'en Alsace ( ?)

Bricou pleine nuit: nous allons descendre aux Islettes, d'où à pied sur Saint-André. Ou en autobus (?)

$\mathrm{Ne}$ passons pas Chaumont. Tant pis

(Mardi 26)

Jour: Bologne. Jus. Neige partout. Ciel brun. Maisons jaunes Joinville. Robert Espagne Après Mogneville, premiers trous d'obus. Ce qui reste du clocher de Révigny. »
« $(. . .)^{\circ}$ On reformera le régiment là, et puis nous les mettrons le 20 février, devant Verdun; et de là, nous pousserons droit jusqu'en Alsace.

- Toujours l'Alsace! Enfin si ça les amuse, laissez-les dire" Encore un arrêt; pleine nuit: c'est Bricou. La neige tombe depuis un certain temps. Il paraît que nous descendrons aux Islettes, pour gagner de là Saint-André à pied ? ou en autobus?

Bologne. Le jour est venu, la neige est épaisse déjà, et rend plus immense et plus déserte cette gare toute jaune et noire. Le ciel est brunâtre, comme la lumière de notre falot, lequel m'est d'ailleurs tombé sur la tête; il s'est éteint et on ne l'a pas rallumé. On nous distribue le jus: je déboucle ma gamelle de mon havresac.

Joinville, Robert-Espagne, M vers le nord, vers la guerre froide et grise. Déjà dans les champs on voit des trous de marmites, d'avant la Marne. On les a laissés là, béants dans la terre douce, dans les prairies calmes. C'est pourtant peu d'ouvrage, boucher un trou! - Non, la guerre est une [rayé dans le manuscrit chose si forte et si dure, qu'elle reste marquée là, dans cette saison tardive et morte.] Il me semble que s'il n'y avait pas la guerre, il y aurait moins d'hiver, ici. Voici le clocher de Revigny tout déchiré, et des maisons écroulées, et un pont coupé qu'on a refait en charpentes de bois: le train y passe sur la pointe des pieds. Au fond, ces ruines ne m'émeuvent pas plus (...)»

\section{« I \\ La Neige \\ I}

Quand le train passe en gare de Bologne sur Marne le jour [rayé est venu] paraît enfin ;

la neige de cette [rayé de la] nuit [rayé rendait plus immense et plus] rend plus sombre et plus déserte la bâtisse, toute jaune et noire. Le ciel de janvier est [rayé brunâtre] terreux, comme la clarté [rayé mourante que] versée [rayé versait] dans notre compartiment par un falot à huile [rayé le falot s'est éteint tout seul avant/qui vient] près de s'éteindre [rayé tout seul]. Nous prenons décidément la direction de l'Argonne; le 46 [rayé régiment] s'y est fait écharper il y a quinze jours; nous allons le renforcer. Nos compagnons de voyage, blessés de l'automne dernier, parlent de la grande forêt triste; Chenut et moi, nous écoutons [rayé des] ces noms inconnus: [rayé et lugubres,] des noms lugubres de ravins, de chaussées, de carrefours, de calvaires. Une énumération d'un romantisme grisâtre et glacé.

***

La matinée s'écoule [rayé Des heures passent] - Revigny, Givryen-Argonne, Sainte-Menehould, les Islettes... Le roulement râpeux du train se traîne et ralentit encore.

Vers une heure, nous arrivons à Clermont-en-Argonne. [rayé Nous quittons enfin les dures banquettes qui nous (...) meurtrissent on va quitter cette boîte capitonnée]. Nous sautons [rayé de notre boîte] du wagon où se fige une odeur de drap crasseux et de vieille pipe froide. Un clairon donne quelques coups de langue. On range les hommes sur le quai et sur la route qui s'élève, sinueuse, vers la ville meusienne. » 
63 des événements. À cet égard, il se présente comme une base progressivement dilatée et remaniée lors des étapes successives de réécriture, entre 1917 et 1918. La première réécriture, notée 2 , reste fidèle à l'ordre chronologique, reprenant notamment, pour la date du 25 janvier, la mention concernant le $46^{\mathrm{e}}$ régiment d'infanterie «à pousser devant Verdun ", et "de là jusqu'en Alsace ». 2 introduit cependant une intervention dialogique à l'intérieur du récit, qui n'était pas dans 1 : «Toujours l'Alsace! Enfin si ça les amuse, laissez-les dire" ». Pézard semble ainsi reconstituer à partir des notes du journal une conversation dont il a gardé le souvenir et dont serait issue l'information simplement mentionnée sur le carnet.

3 procède en revanche, par rapport aux deux étapes antérieures, à une sévère rétraction chronologique, faisant débuter le récit (le livre) au 26 janvier. Tout l'amont du voyage en train est donc occulté. Pour autant, certains des éléments narratifs qui figuraient à la date du 25 dans le carnet (dont le secours à apporter au $46^{\mathrm{e}}$ d'infanterie) sont intégrés au récit, au prix d'une rupture avec le strict cours journalier du carnet, voire du récit 2 , et à la faveur d'ellipses et d'analepses qui démarquent strictement le livre du journal.

651 n'en demeure pas moins le squelette où sont disposés pour une utilisation ultérieure les éléments essentiels que $\mathbf{2}$ et $\mathbf{3}$ développent. Une simple liste en $\mathbf{1}:$ « Jour : Bologne. Jus. Neige partout. Ciel brun. Maisons jaunes » donne ainsi lieu à des reprises, dans 2 et 3 où les évolutions le disputent aux éléments de continuité. Le « ciel brun » (1) devient «brunâtre » en 2 , reste "brunâtre » dans la première rédaction de 3 , que l'on notera $\mathbf{3} \mathbf{1}$, avant de se transformer en " ciel terreux » en $\mathbf{3} / \mathbf{2}$ - l'évocation visuelle de la terre, qui ne fait plus l'objet d'une description à proprement parler dans les versions « postjournal ", se trouve ainsi "rattrapée » par une forme allusive plus conforme à l'indistinction des éléments qui caractérise le paysage décrit.

Un élément demeure en revanche commun aux trois textes, mais se trouve dilaté, passé à l'avant-scène, puisqu'il est inscrit dans le titre même du manuscrit de Vauquois (3) : la neige.

De manière plus générale, 3 s'affranchit de choix qu'appelait assez naturellement la grille narrative ébauchée dans 1 et qui s'affichaient clairement en 2 . Ainsi l'attention aux détails des paysages gagne en importance dans $\mathbf{2}$ pour s'effacer dans $\mathbf{3}$ - les trous d'obus notamment, la terre, disparaissent totalement en 3. De même, l'énumération des noms des villes traversées demeure, certes, d'un texte à l'autre, mais en 3 l'identification des localités perd en relief, certains toponymes sont omis ( Joinville, Robert-Espagne, Mogneville », présents dans 1 et 2). Revigny est simplement cité, sans plus de mention de son clocher dont les ruines étaient évoquées en $\mathbf{1}$ et $\mathbf{2}$. Il est possible de trouver à cette indifférence nouvelle une explication à la fin du feuillet correspondant dans 2: «Au fond, ces ruines ne m'émeuvent pas plus». Est-ce à dire que, de ce que sa mémoire et sa plume ont conservé, Pézard ne garde que ce qui l'émeut?

68 D'autre part, 2 introduit des éléments, dont certains « vérifacteurs » renvoyant à la vie des hommes, qui n'étaient pas dans le journal (1), mais qui seront repris en 3, avec des remaniements, voire des remaniements à l'intérieur même du manuscrit (entre $\mathbf{3 / 1}$ et 3/2), c'est-à-dire au cours de la conception de Vauquois. Par exemple : 

fonde, bien entendu, sur la documentation personnelle qu'il constitue sur le front et dont nous avons vu les déclinaisons. À cela viennent s'ajouter un certain nombre de "sources complémentaires", notamment cartographiques et iconographiques, sur lesquelles il appuie la reconstitution du cadre et du contexte où son récit s'insère.

Cette documentation est constituée de documents originaux ou copiés d'originaux produits par André Pézard, mais pas uniquement; y sont joints des témoignages qui lui parviennent parfois bien après la guerre elle-même, directement ou via les amicales d'anciens combattants. Dans ce dernier cas, la documentation recueillie est mise à profit pour amender le texte en vue d'une réédition. La démarche d'André Pézard procède alors d'un véritable "travail collaboratif», au service de la vérité. Cette exigence constante qui est la sienne justifie également le soin qu'il prend à conserver ces diverses sources, réunies pour une grande part dans des dossiers dont les archives conservent l'unicité. 


\section{Diversifier, multiplier les sources}

77 Initialement rangés et conservés ensemble dans un portefeuille de cuir retrouvé dans sa maison de Brantes, dans le Ventoux, les documents conservés sous la cote 691 AP/4 ont manifestement permis à l'auteur de Vauquois de reconstituer précisément chaque étape de son engagement : positions militaires, situation du terrain, combats, hommes. S'y trouvent en effet, outre les cartes d'état-major, des plans manuscrits annotés, portant parfois mention du modèle sur lequel ils sont copiés, du moins de la date à laquelle l'état décrit correspond ${ }^{9}$, ainsi que des relevés en coupe de la butte, polycopiés à partir de dessins originaux. À titre plus anecdotique, Pézard aura également conservé, dans une enveloppe, un fusée française avec son parachute de soie blanche ou encore un bandage de blessé. À ce matériau qui concerne directement les opérations militaires dont est constitué l'arrière-plan de Vauquois s'ajoutent des poèmes, des cartes postales et des photographies, évoquant directement la vie des soldats, leurs maux, leurs camaraderies et leurs loisirs. Une tension entre deux modes d'appréhension de la bataille, l'un surplombant, factuel, l'autre plus intime, au plus près d'un vécu forcément subjectif, est lisible, que le livre résout en adoptant une focale narrative extrêmement rapprochée.

Chacune de ces pièces peut être considérée comme une sorte d'outil mnémotechnique à partir duquel le processus de remémoration des faits est rendu possible. Ce processus se prolonge au reste bien au-delà de la première édition de 1918. Les archives d'André Pézard témoignent en effet d'un inlassable travail d'amendement du texte de Vauquois.

\section{La quête de la vérité}

C'est sans doute à l'occasion du travail effectué en collaboration entre Pézard et Paul Fischmann pour la traduction en allemand de Nous autres à Vauquois ${ }^{10}$ que l'auteur se donne le temps de remettre l'ouvrage sur le métier. Mais c'est après coup, passé les cinq ans d'échanges épistolaires avec son traducteur auquel, en bon germaniste, il suggère des modifications, que Pézard est amené à relever ce qu'il considère alors comme une incohérence figurant, non seulement dans l'édition originale de Vauquois, mais aussi dans son journal de guerre - preuve s'il en était besoin que c'est bien de là que le livre tire sa source tout en la corrigeant si besoin (fig. 21) :

20 septembre 1936 Limonest

Il me semble, au bout de vingt ans, que j'ai fait une erreur pour corriger une erreur. Mon carnet, à la date du 20 sept. 1916 dern. page note ligne 6 : il est 18 heures puis* deux dernières heures : $6 \mathrm{~h} 45$, enfin $18 \mathrm{~h} 15$. vérifié sur le carnet*

Ce qui est impossible.

Le livre accepte comme bonne la première qu'il rétablit : 18h45 parce que plus haut il y a : il est $18 \mathrm{~h}$ et ça tombe..., et corrige la seconde, pour la mettre d'accord avec l'autre, sous cette forme : $19 \mathrm{~h} 15$.

Oui, mais je vois aujourd'hui qu'à 19 h15 heure d'été (nous l'avions en 1916) la nuit est presque tombée. Or quand j'ai été blessé il faisait grand jour; et la nuit m'a semblé bien longue à venir.

N'ai-je pas écrit : $16 \mathrm{~h} 45$ et 18h15 ? (et d'ailleurs, que dit le ms de sept. 17 ? Vois.

Mon certificat d'origine de blessure ne prouve rien * dit : $17 \mathrm{~h} 30$ mais a dû être rédigé suivant mes indications pour signifier 18h30?.?

Seulement en octobre 16 quand a été établi le cert.* j'étais encore à la Pitié et n'ai pas dû regarder mon carnet. (691 AP/4, Note annexée à un exemplaire du livre dans sa dix-huitième édition) mentions ajoutées dans un second temps*) 
Plus loin sont portées les mentions suivantes, d'une écriture plus tardive :

Le carnet de poche <NDLR : voir journal de guerre> dit

1. $5:$ il est 18 heures

puis : $6 \mathrm{~h} 45^{\circ}$ Paoli serait tué il faut sans doute lire $6 h .5^{*}$

18 h15 Bertho mortellement blessé

Ma note du 20 décembre 1916 ne parle pas d'heure, mais à la p. 4, on lit : "Nuit"

Calcul impossible

À quelle saison le changement d'heure?

Figure 21

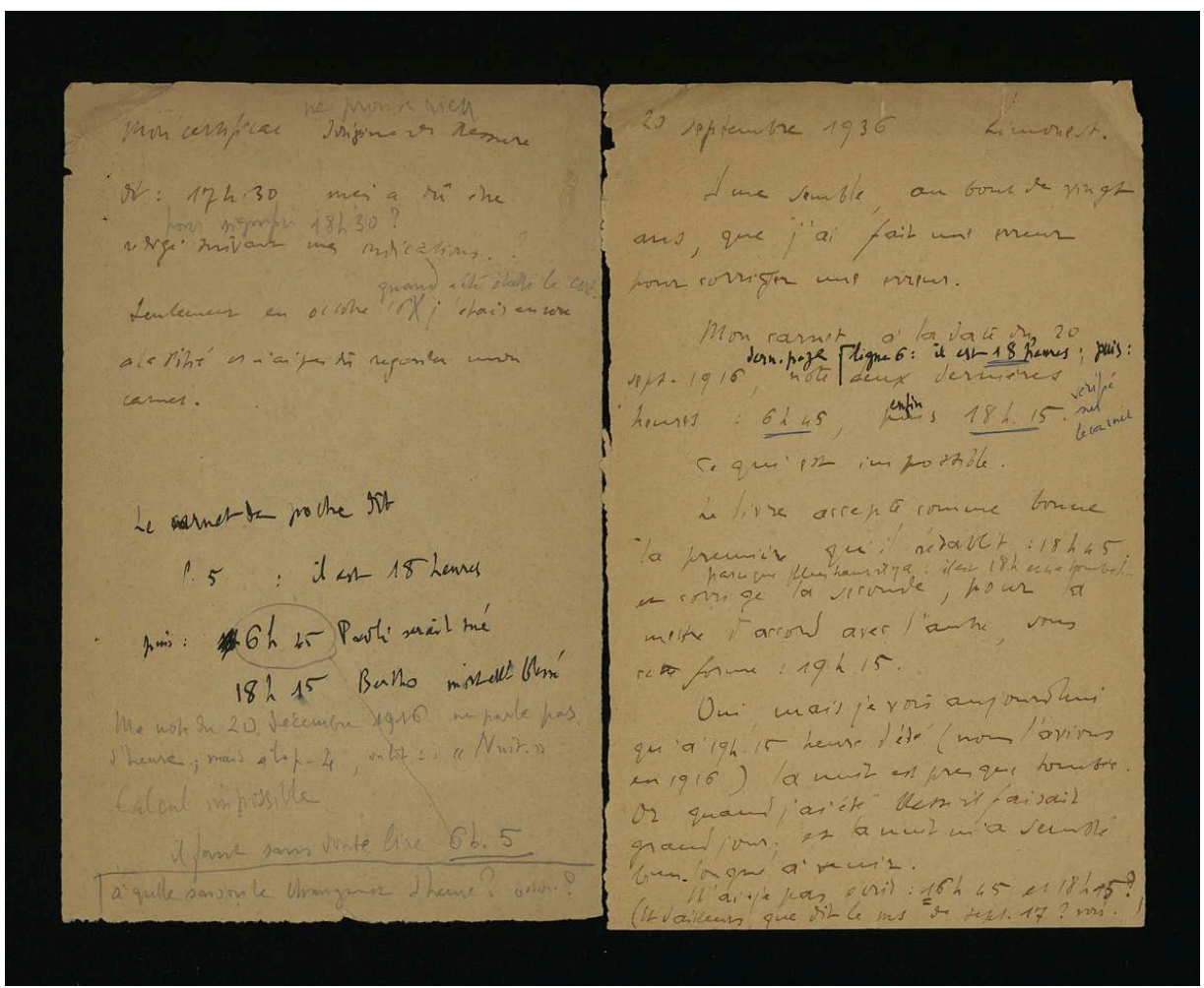

Notes et corrections de 1936 sur Vauquois.

(c) Archives nationales.

81 Pézard met ainsi à distance son propre travail d'écriture, dont il en vient à contester la véracité même. Il ne parvient cependant pas à trouver le fin mot de l'énigme quasi policière à laquelle il se livre ici. La révision du livre en vue de la réédition de 1975 retient finalement l'hypothèse que dictent la cohérence chronologique, le déroulé des événements tels que les reconstituent les différentes phases de rédaction du journal et du livre, laissant de côté les bribes émanant d'une mémoire sensorielle dont le contenu reste invérifiable (fig. 22).

Ainsi l'exemplaire corrigé en 1975 porte les mentions suivantes (les corrections manuscrites portées par Pézard sur la copie de la $20^{\mathrm{e}}$ édition publiée à La Renaissance du Livre sont identifiées par le soulignement) :

18h.45? - Le lieutenant *** Paoli est tué. La tête emportée. Je suis allé le dire à Rey et à Chalchat. Nous nous regardons.

19h.15. - Usine à carnage, ce bois pauvre.

Le capitane $\mathrm{C}^{* * *}$ Condroyer blessé. (691AP 15) 
Figure 22

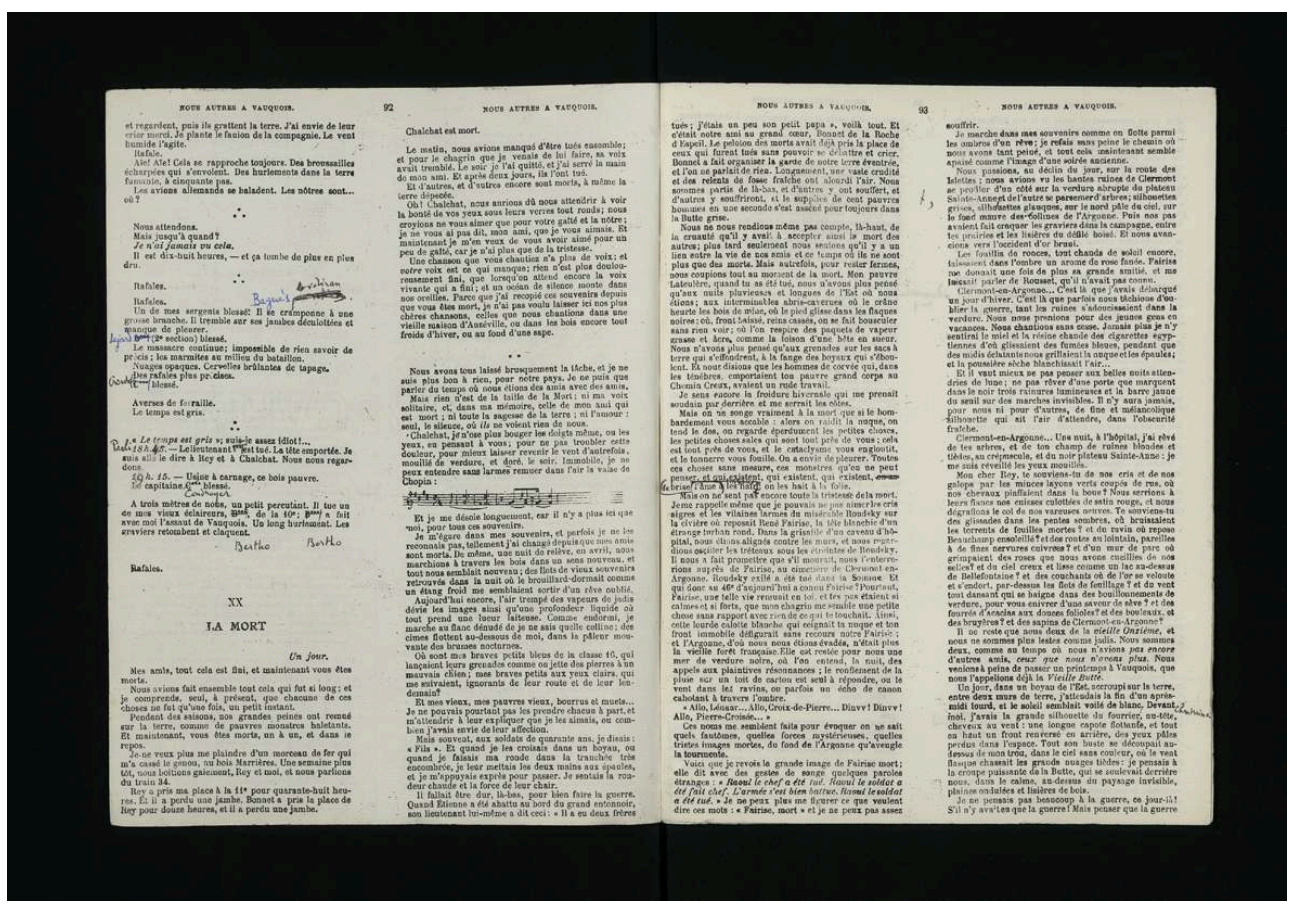

Corrections en vue de l'édition de 1975

(c) Archives nationales.

83 Au passage, notons les traces que laisse, d'une édition l'autre, le passage au temps de l'histoire, permettant à l'auteur d'identifier les combattants, encore désignés par des astérisques dans la première version publiée du texte. Ce dernier s'enrichit en outre de détails que Pézard signale sous forme d'annotations manuscrites, mais aussi de feuillets dactylographiés qu'il insère dans la copie de la $20^{\mathrm{e}}$ édition précédemment mentionnée (fig. 23) :

84 (691 AP 15, feuillet inséré entre les pages 28 et 29 du livre) «Placer à la page 28, à la fin du chapitre VI, un appel de note ${ }^{\circ}$, et au bas la note suivante :

Note de 1973. - Du 21 mars au 2 avril 1915, quelques misères physiques, et des rancœurs de service dont mon carnet 2 garde la trace, rendaient un son ingrat. En rédigeant le livre, j'ai cru bon de sauter dix pages. Mais au moins, pour éclairer la suite, j'aurais dû noter au 31 mars l'arrivée dans nos compagnies d'une petite promotion de sous-lieutenants, venus principalement des hussards (démontés). Le "nôtre" était mon cher ami Léon Rey, qu'on va voir sortir un peu brusquement. Rey est mort en décembre 1972. 
Figure 23

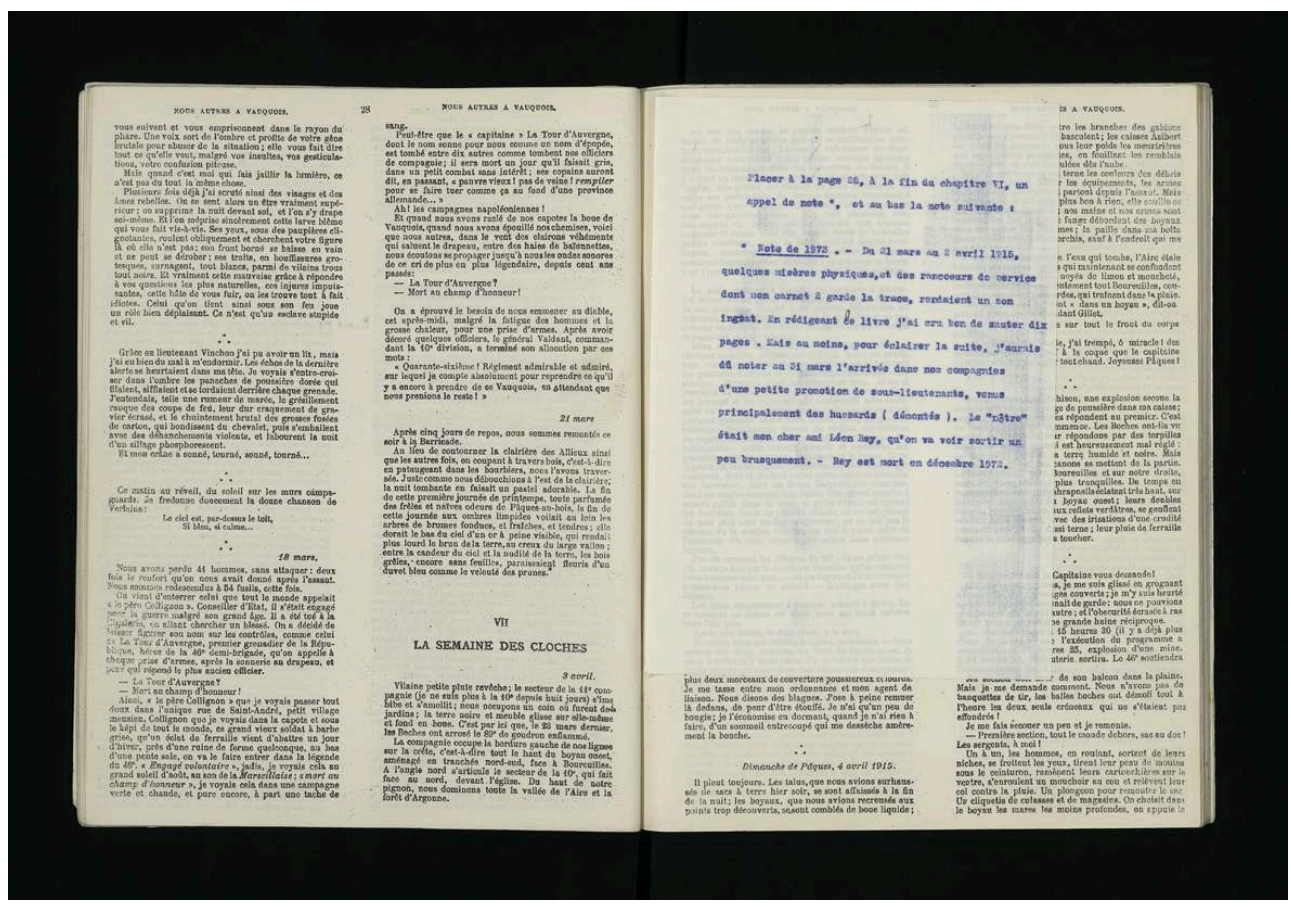

Insertion d'une note en vue de l'édition de 1975.

(c) Archives nationales.

En même temps qu'elle renseigne fort utilement là encore la genèse du texte - le travail opéré entre carnet et manuscrit de Vauquois, cette note montre l'effet notoire que le passage du temps exerce sur la reprise du texte en vue de sa réédition. La mort récente de Rey est en effet tout sauf étrangère à l'ajout ici voulu par Pézard.

Soixante ans après le début de son engagement, repentirs et ajouts viennent enrichir cette réédition de Vauquois : un livre que son auteur tient pour toujours perfectible, amendable - du moins, au plan des faits relatés. Cet attachement à l'exactitude du récit, Pézard le partage avec les amicales de combattants, dont il est un membre assidu. Plusieurs décennies après le conflit, ces associations continuent, plus que jamais, de recueillir, de conserver et de diffuser à leurs adhérents la mémoire qu'elles contribuent à collecter auprès d'anciens soldats. Le fonds conserve ainsi la trace de courriers adressés à Pézard par, notamment, le Comité commémoratif de l'Argonne. Apprenant la réédition à venir de Vauquois, le président du comité, le général André Rouyer, envoie à l'auteur, par une lettre du 11 janvier 1974, à titre d'illustration, des photographies annotées, "prises le 28 février 1915 par le Docteur Vincent qui accompagna la $8^{\mathrm{e}}$ Compagnie ». L'une d'entre elles comporte, de la main même de Rouyer, la mention suivante (fig. 24, 25) :

$8^{\mathrm{e}}$ Cie du $46^{\mathrm{e}}$ RI. 28.2.1915. Dr Vincent

Sur le sol le musicien Delaittre, la carotide ouverte par un projectile alors que la musique jouait la Marseillaise. Le docteur Vincent vient de ligaturer l'artère. Selon le S/Lt Boucheron, dans "L'assaut ", un obus explosant dans le chemin creux décapitait Delaittre et tuait ou blessait plusieurs soldats. 
Figure 24

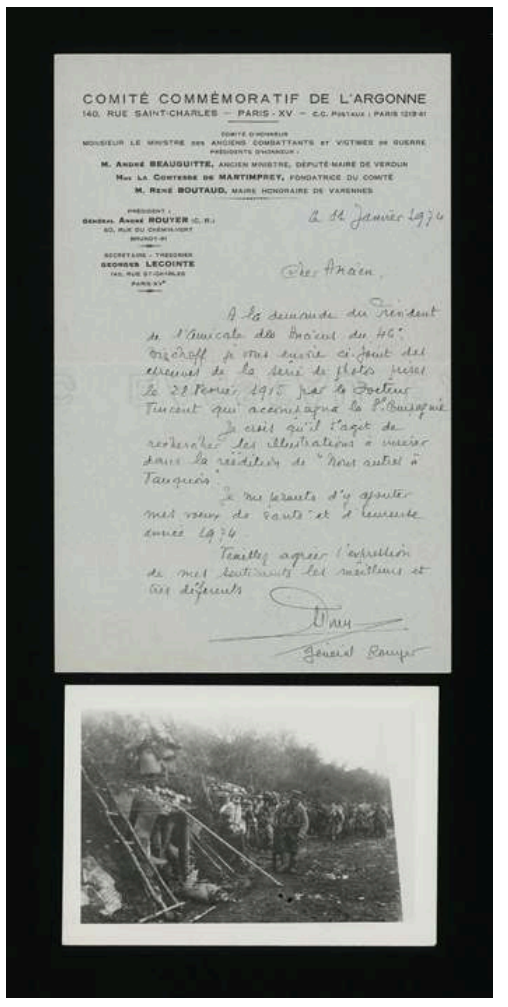

Lettre du général Rouyer du 11 janvier 1974 et photographie réalisée le 28 février 1915. (c) Archives nationales. 
Figure 25

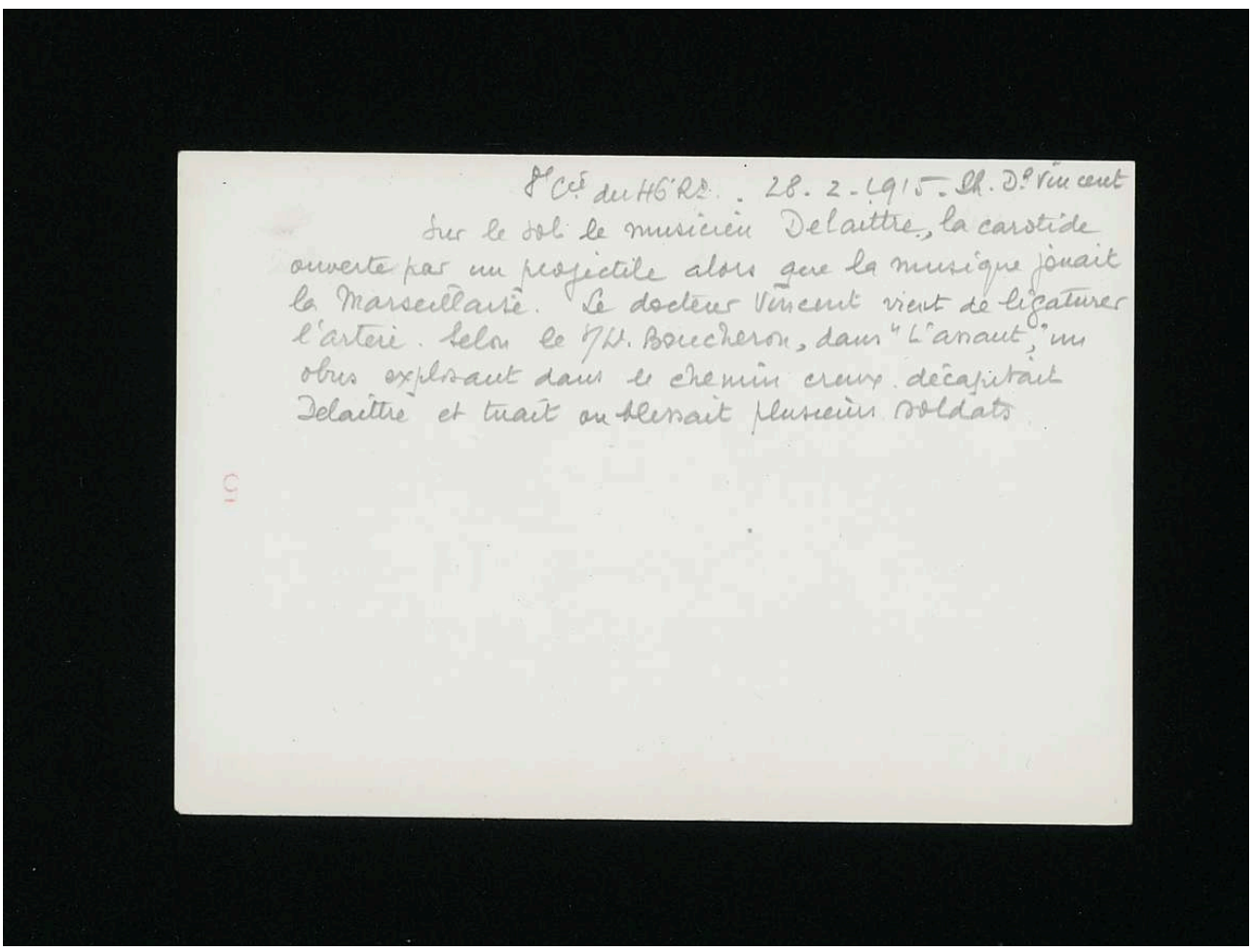

Verso de la photographie du 28 février 1915, légendée par le général André Rouyer.

(c) Archives nationales

Photos et récit de témoin à l'appui, l'envoi du général Rouyer met directement en cause un récit publié - ici L'assaut, l'Argonne et Vauquois avec la 10e division, 1914-1915 de Georges Boucheron (Paris, 1917). Sans le dire explicitement, la note de Rouyer met en évidence la façon dont le sous-lieutenant a travesti la réalité, laissant planer un doute raisonnable sur l'ensemble de son récit. Plus de trente ans après Témoins, l'exigence de vérité demeure aussi forte chez les anciens combattants et les lecteurs de la Grande Guerre qu'elle l'était pour Norton Cru dans Témoins. Cette attention portée aux détails, à l'exactitude des faits permet d'expliquer les repentirs et le doute méthodique auquel Pézard soumet ses propres écrits, trouvant parfois auprès des amicales des supports documentaires précieux.

Plus largement, Vauquois et ses éditions successives offrent à son auteur l'occasion d'échanges et de rencontres qui contribuent à conserver vivant le souvenir de la Grande Guerre, à l'actualiser, faisant du fonds Pézard le réceptacle d'une mémoire en expansion.

\section{Polyphonie mémorielle}

89 Cette mémoire, l'auteur la cultive résolument, après la publication de Vauquois, en entreprenant au milieu des années 1920 la rédaction de plusieurs "monuments" dédiés aux écrivains morts à la guerre. Le fonds (691 AP/4) en conserve les brouillons manuscrits, projets d'articles publiés dans le bulletin de l'amicale de Vauquois. 
Figure 26

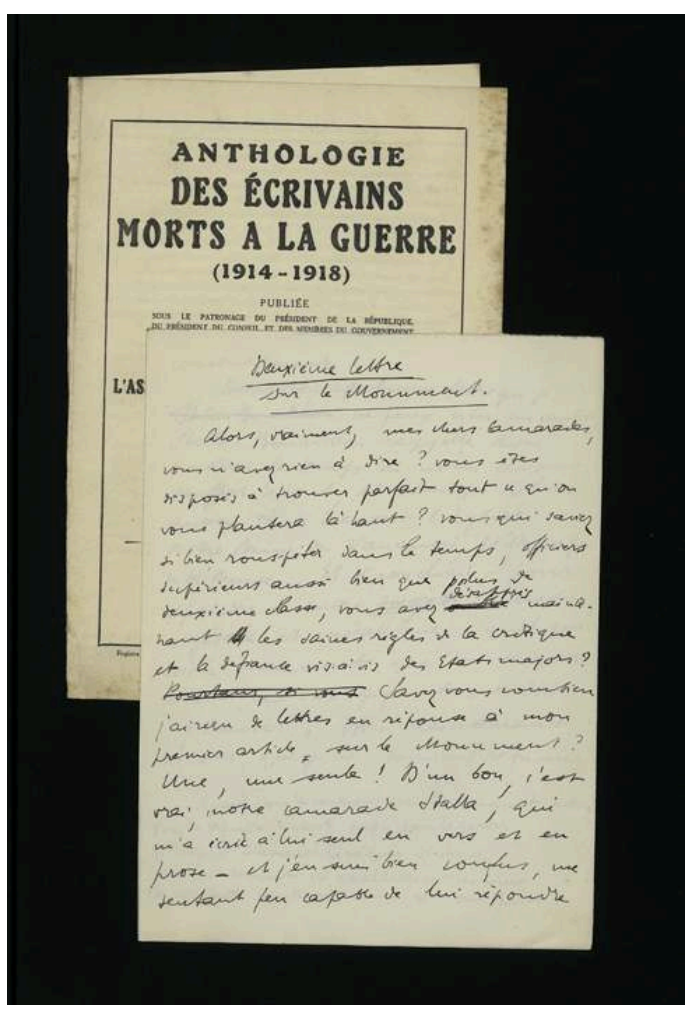

Brouillon du « Deuxième monument ».

(c) Archives nationales.

90 Aux amis morts que célèbre et pleure l'épilogue du livre viennent se joindre les « amis de plume » que reconnaît Pézard dans ces écrits, dont le second, intitulé Deuxième lettre sur le monument comporte cet incipit (fig. 26) :

Alors, vraiment, mes chers camarades, vous n'avez rien à dire ? Vous êtes disposés à trouver parfait tout ce qu'on vous plantera là haut? Vous qui saviez si bien rouspéter dans le temps, officiers supérieurs aussi bien que poilus de deuxième classe, vous avez désappris maintenant les saines règles de la critique et la défiance vis-à-vis des États-majors ? Savez-vous combien j'ai reçu de lettres en réponse à mon premier article sur le Monument? Une, une seule! D'un bon, c'est vrai, notre camarade Stalla, qui m'a écrit à lui seul en vers et en prose - et j'en suis bien confus, me sentant peu capable de lui répondre.

91 Rédigé à la manière d'une adresse aux morts, dont Vauquois était déjà coutumier, le texte sorti en 1922, fait mention du premier article publié par Pézard pour le bulletin de Vauquois et déplore ce qu'il semble considérer comme un désintérêt du temps pour la mémoire des combattants morts. L'auteur y mentionne les envois de Jules StallaBourdillon, avec lequel il demeurera en contact permanent - ce dont témoigne la correspondance privée reçue par Pézard (691 AP 9). Car, et c'est là un des traits caractéristiques du fonds conservé, les écrits qu'il publie concernant la Grande Guerre lui permettent d'entrer en contact avec des correspondants, comme lui anciens combattants, qui jouent, pour Pézard et pour le souvenir qu'il cultive du conflit, un rôle essentiel.

92 Au premier rang d'entre eux se trouve, bien sûr, Jean Norton Cru dont la plupart des lettres à André Pézard sont conservées dans le fonds - aussi bien que des tapuscrits de Témoins, que Pézard contribua à relire, et des pans entiers de revue de presse 
concernant le livre. Il est vrai que Pézard aura ainsi participé à l'achèvement de cet ouvrage colossal, réunissant quelque 300 témoignages de soldats ainsi promus comme un matériau essentiel à l'écriture de l'histoire du premier conflit mondial. C'est pourquoi sans doute Cru a soin d'informer Pézard, presque en temps réel, des retours de presse, abondants, que le livre ne laisse de susciter - avis toujours tranchés, l'éloge le disputant aux réactions les plus vives.

Cru s'enorgueillit dans ses lettres à Pézard de ce qu'il a contribué à promouvoir « les meilleurs " des récits de guerre - meilleur, entend-il, au titre de leur exactitude documentaire - et qu'il a su réunir des auteurs comme Genevoix, Pézard et Cazin ${ }^{11}$ (fig. 27). C'est ainsi non sans orgueil qu'il écrit à Pézard, à la date du 31 décembre 1929 :

Ce que vous me dites de Cazin me touche plus que vous ne le pensez peut-être. Je suis très fier que Témoins puisse avoir servi de trait d'union entre deux hommes dignes de se connaitre, mais que notre société, arrangée en catégories, tend à maintenir séparés (l'un catholique actif, l'autre... ce que vous êtes). Je vais être affreusement indiscret... Pourriez-vous, sans trahir Cazin, qui s'est d'ailleurs longuement confessé à moi en 1926, me recopier certains passages de ses lettres? J'apprécierai beaucoup votre marque de confiance et je la mériterai. Je ne sais comment vous faire comprendre la satisfaction que j'aurais. Vous êtes l'un et l'autre mes auteurs ; à votre égard j'éprouve quelque chose de la paternité. Les sentiments nés d'une communion en Témoins sont de nature à fortifier ma foi et à l'élargir.

Figure 27

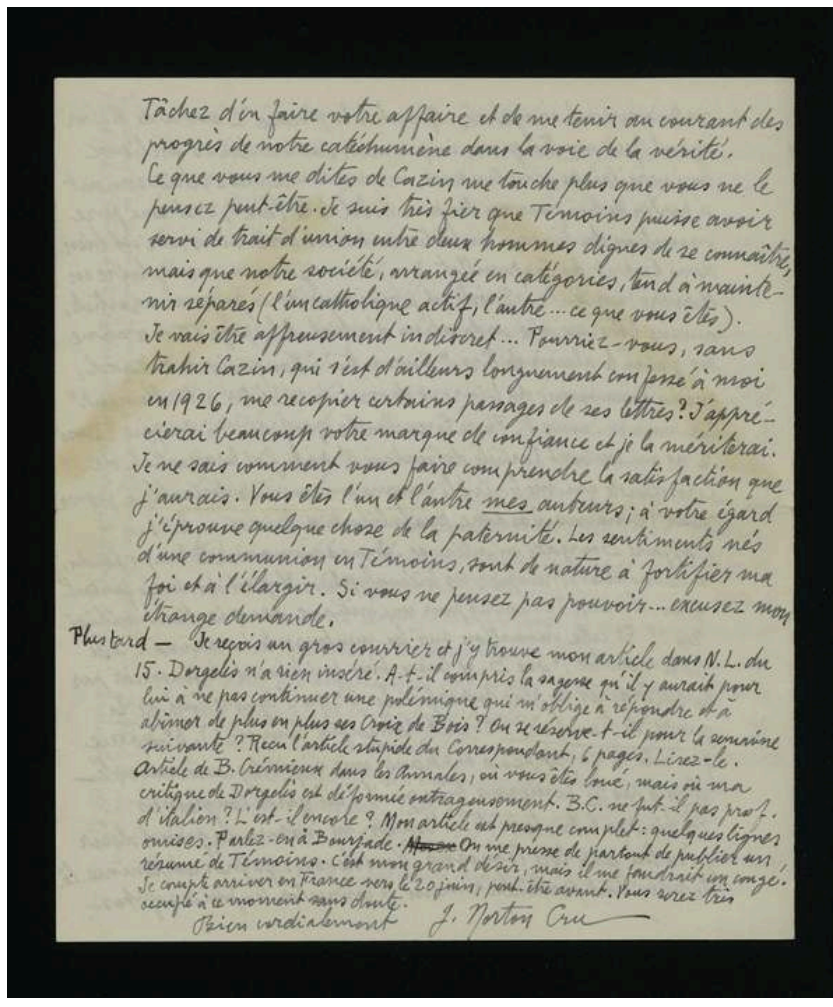

Lettre de Jean Norton Cru du 31 décembre 1929.

(c) Archives nationales.

En effet, à cette date, l'auteur de Vauquois est déjà entré en contact avec celui de L'humaniste à la guerre, ce dont témoigne la première en date des lettres conservées de Paul Cazin à Pézard (fig. 28, 29) : 
« Paris, 7-11-29

Cher André Pézard, on me fait suivre ici votre aimable mot. C'est par Norton-Cru que je vous ai connu et depuis, je veux à tout prix lire votre Vauquois [...]».

Figure 28

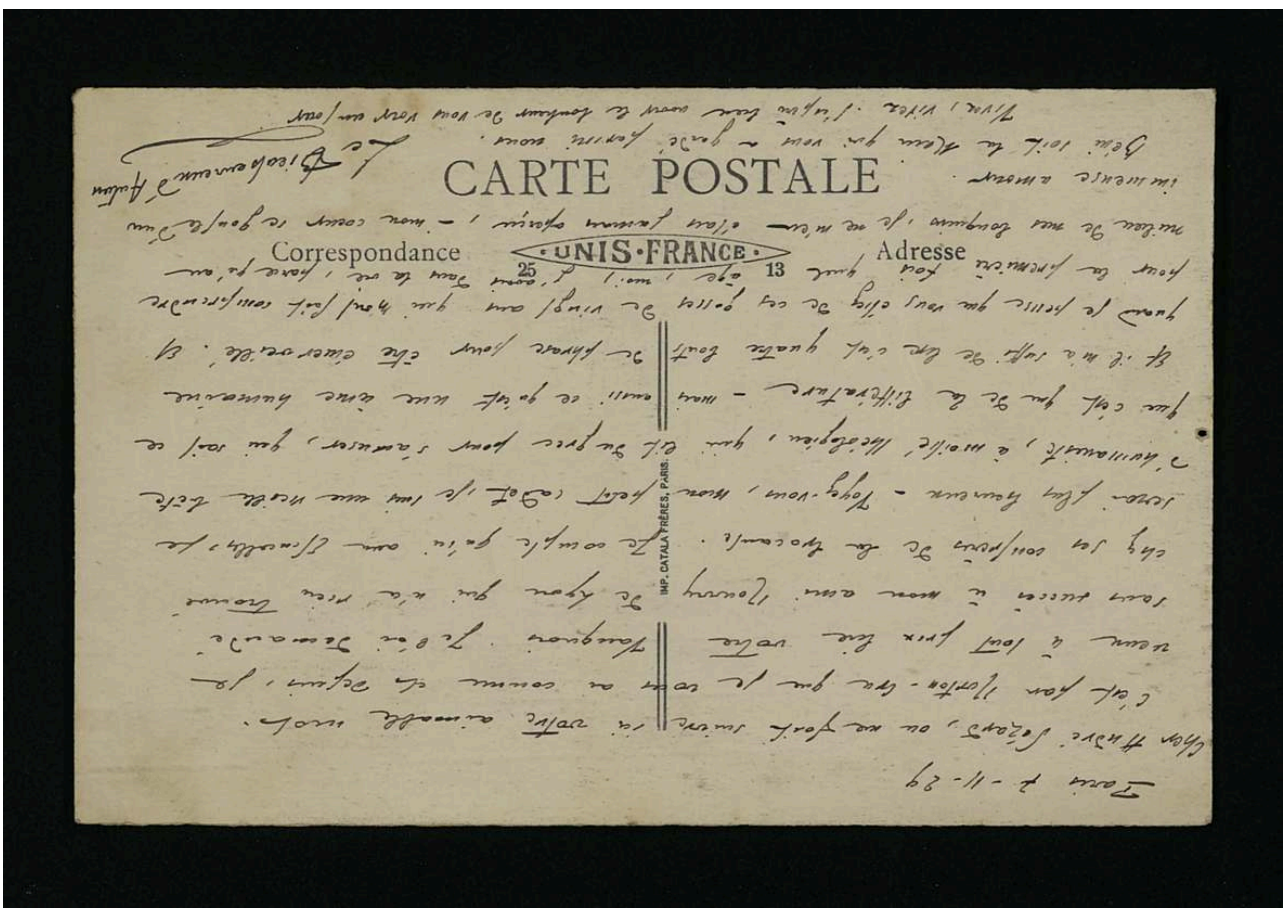

Carte de Paul Cazin comportant sa photographie (7 novembre 1929).

(c) Archives nationales. 
Figure 29

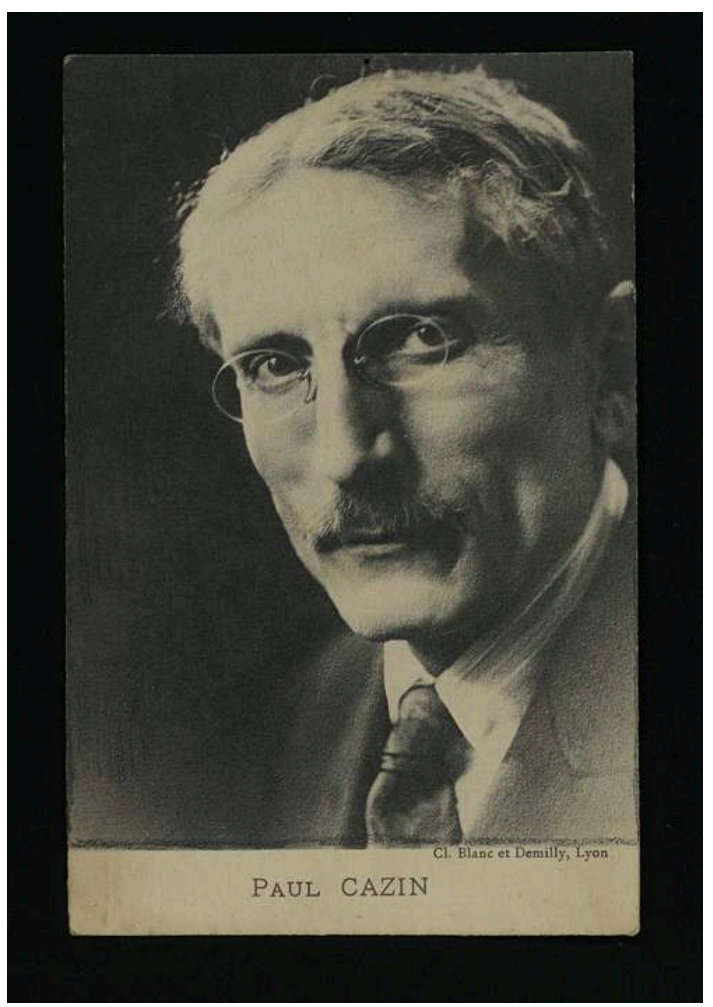

Carte de Paul Cazin comportant sa photographie (7 novembre 1929).

(c) Archives nationales. effet entre les deux hommes une véritable passion amicale très vite émancipée de la «tutelle paternelle» de Norton Cru. Paul Cazin prend au reste quelque distance à l'égard du battage médiatique que suscite le conflit entre Cru et les auteurs dépréciés dans Témoins (Barbusse, Dorgelès...). La correspondance, encore inédite, qu'il adresse à Pézard en témoigne :

Bruit dans Landerneau à propos de Cru. Une carte de Dorgelès accompagnant un plaidoyer m'invite à prendre parti. Et hier encore à mon retour, je trouve une feuille de Hollande sur laquelle je dois graver mon hommage au grand homme. Je ne dis pas qu'il n'ait un immense mérite, mais ce battage devient insupportable, vraiment. Et tout cela payé. Zut, zut, à la fin.

De la place pour tous (Cazin à Pézard, 15 janvier 1930).

97 Cazin doute au demeurant que le livre
témoignages qu'il élit de préférence :

Mais je crois impossible que le mouvement «Cru» n'atteigne au moins ce résultat de mettre en librairie d'une façon permanente les meilleurs témoins de la guerre qu'on les trouve au moins, bon Dieu, quand on les cherche. J'en ai parlé à Paris avec Victor Méric (!) au Merle. Il voudrait dégotter pour Cru le Nobel de la Paix (Cazin à Pézard, 21 janvier 1930).

Pézard n'affiche jamais cette légère distance, quelque peu teintée d'ironie, que manifeste Cazin à l'égard de Cru. C'est qu'il est, plus que l'érudit polonisant, impliqué directement dans la publication de Témoins. Il n'en demeure pas moins que les échanges entre les trois hommes, dont le fonds Pézard en sa correspondance constitue le point 
nodal, offrent concernant Témoins, sa réception et ses conséquences au sens large des informations primordiales.

La «querelle de Témoins" telle qu'elle se devine sans peine derrière ces correspondances croisées, mais aussi, plus largement, le retour mémoriel que tous ces écrits de guerre suscitent, leurs enjeux, sur plusieurs décennies, trouvent à s'exprimer de manière privilégiée dans le fonds Pézard.

La postérité littéraire de Vauquois, son succès durable des deux côtés du Rhin, "polarisent » en effet les témoignages dont le fonds se trouve, ipso facto, le point de rencontre et le dépositaire, prolongeant ainsi l'œuvre initiée par Cru et ses trois cents témoins.

Outre en effet l'intéressante correspondance entre Pézard et son traducteur allemand, Paul Fischmann (22 septembre 1930-15 mai 1935) ${ }^{12}$, le carton 691 AP/4 conserve les lettres de Max Matzke (12 décembre 1934-29 janvier 1936), lecteur allemand de la traduction et ancien combattant à Vauquois. La première, en date du 12 décembre 1934, est particulièrement éloquente :

Monsieur et cher camarade de guerre,

C'est avec grand enthousiasme que j'ai lu votre superbe livre Nous autres à Vauquois, traduit par le Dr Fischmann, Berlin, à qui je dois votre adresse.

En observateur d'artillerie, j'étais presque vis-à-vis de vous dans la tranchée à la lisière du Bois de Cheppy. Comme vous, j'ai écrit un livre journal, seul pour moi, dès mon arrivée à ce secteur en novembre 1914 jusqu'à mon départ en septembre 1915. Tous les grands événements de combat, que vous décrivez dans votre journal sont aussi consignés dans le mien. J'ai collationné vos annotations des miennes et trouvé, qu'elles sont très exactes. Presque tous les lieux, dont vous faites mention dans votre livre, étaient les buts de tir de notre batterie. Nous avons souvent tiré sur Vauquois et parfois aussi sur Aubréville, près de votre quartier Parois.

Côté allemand comme français, un ancien combattant a, avant tout, le soin du détail vrai, de l'exactitude vérifiée des faits. Matzke témoigne aussi dans ce courrier d'une pratique courante chez les soldats : la tenue d'un carnet de guerre consignant assez précisément les opérations, les " grands événements de combat ». Ce sont là des traits communs aux deux hommes, propres à transcender, dépasser des antagonismes que pourrait raviver un contexte politique allemand plus que défavorable.

Aux lettres de Matzke s'ajoutent toutes celles, isolées ou constituant un ensemble suivi, de lecteurs-acteurs. Bien souvent des récits manuscrits ou dactylographiés inédits s'y trouvent joints, tel celui de Delavaux, envoyé le 12 avril 1968, retraçant les « les longues heures du $117^{e} \mathrm{RI}$ » à compter de mai 1917 (691 AP 14). Destinataire de tous ces récits, Pézard en assure dès lors la conservation, à terme la transmission puisqu'ils figurent parmi les ensembles documentaires qu'il destine lui-même, avant sa mort, à être transférés aux archives du Collège de France.

\section{Conclusion}

La constitution du «fonds Pézard» concernant la Grande Guerre correspond à des temporalités distinctes. Autour d'un noyau dur constitué d'écrits exactement contemporains des événements, "pris sur le vif» par lui-même, Pézard rassemble, compose, ajoute : ses propres articles et ouvrages composés "après coup ", mais aussi un matériau qu'il se procure pour améliorer la connaissance d'événements vécus, subis, 
qu'il s'agit toujours de comprendre - rien chez Pézard n'évoque en effet la posture d'un Fabrice à Waterloo.

Les archives témoignent ainsi, de manière privilégiée, d'une évolution personnelle et intellectuelle face à la guerre. Très soigneusement et exhaustivement conservés, carnets, journaux, lettres, photographies, manuscrits, etc. forment un poste d'observation unique pour qui entreprend l'étude génétique de l'œuvre publiée, Nous autres à Vauquois comme d'autres récits.

Surtout, les archives de la Grande Guerre, chez Pézard - et il n'est pas interdit, vu les traces et les reprises, l'enchevêtrement temporel auquel il les soumet lui-même, de penser qu'il s'agit là d'un parti délibéré - matérialisent une mémoire en expansion, qui prend appui sur l'écrit éventuellement «fixé », pour un temps, par la publication, pour le dépasser, le nourrir de souvenirs affleurant à nouveau à la conscience, donc à l'écriture, souvenirs personnels, mais aussi mémoires allogènes, dont le fonds conserve la trace. L'enjeu mémoriel renouvelé du témoignage de Pézard se lit dans cet accroissement documentaire, signe d'un intérêt constant pour Vauquois, «œuvre en progression ", de sa première édition en 1918 jusqu'à la mort de l'auteur, qui clôt le fonds, en 1984. Autour de cette mémoire publiée, rééditée, d'autres viennent se joindre, comme par accrétion, qui parviennent à Pézard via le courrier de ses lecteurs.

Où s'arrête, se demandera-t-on, le for privé de la Grande Guerre ? En 1918, après les derniers ajouts et corrections apportés alors aux témoignages publiés? Ou après épuisement des débats, des réactions, des adhésions qu'ils suscitent?

Temps du témoin et temps de l'historien, dans ces conditions, se confondent, et ce matériau, littéraire mais aussi proprement historique mérite d'être considéré non pas isolément, mais au sein d'un réseau que forme l'ensemble hétérogène des scripteurs, auteurs, associations, simples lecteurs eux-mêmes témoins et acteurs - ou pas - du conflit. En soi-même, le fonds Pézard éclaire au reste admirablement tous ces aspects. Un jeune historien en a la prescience, qui, le 8 février 1966, écrit à André Pézard afin d'accéder, dans le cadre de ses recherches, au courrier des lecteurs de Vauquois. Par un effet de miroir saisissant, sa lettre se retrouvera parmi les témoignages épistolaires qu'il souhaitait consulter :

Monsieur,

Je prépare ma thèse sur «Les Anciens Combattants et la Société française. 1914-1939» sous la direction de M. le Doyen Renouvin. Mes recherches ont déjà avancé, mais je me heurte à un problème délicat : dans quelle mesure l'opinion des A.C. qui s'expriment traduit-elle le sentiment de l'ensemble des combattants? Les professionnels du mouvement combattant sont-ils des échos fidèles, ou déformants ${ }^{13}$ ?

Malheureusement, les documents font défaut, qui permettraient de répondre à cette question et je songeais à me résigner à la poser sans la résoudre lorsque je me suis avisé qu'il y avait une catégorie de témoignages qui pouvaient m'éclairer : ce sont les lettres adressées aux auteurs de récits de guerre par d'Anciens Combattants.

Aussi je me permets de vous importuner pour vous demander si vous n'auriez pas conservé par hasard les lettres que vous a values la publication de Nous autres à Vauquois et si vous accepteriez de me les communiquer. J'attache à ce livre une grande valeur; c'est pour moi, avec ceux de M. Genevoix ou de J. Meyer un des plus authentiques de l'abondante production en ce genre. C'est pourquoi je crois que la correspondance qu'il a suscitée devrait être intéressante.

En espérant que la conjonction de votre bienveillance et de hasards favorables vous permettront de m'apporter une aide précieuse par la communication de ces 
documents, je tiens à vous remercier d'ores et déjà de l'accueil que vous réserverez à ma demande, et je vous prie de bien vouloir accepter, monsieur, l'expression de mes sentiments les plus respectueux.

Antoine Prost

17 Bd de Verdun

45 Orléans

PS: normalien moi-même, l'annuaire des anciens élèves m'a fourni votre adresse (691 AP 14).

La lettre de l'historien matérialiserait l'ultime strate de ce patrimoine privé en expansion que constitue la mémoire de la Grande Guerre chez Pézard. À moins qu'elle n'appelle à son tour une actualisation, que pourrait constituer la réponse d'Antoine Prost, aujourd'hui, à sa question d'alors - une réponse à annexer aux archives d'André Pézard, inlassable témoin de la Première Guerre.

\section{NOTES}

1. - CRU, Jean Norton. Témoins. Essai d'analyse et de critique des souvenirs de combattants édités en français de 1915 à 1928. Paris, 1929 (première édition). ATTARD-MARANINCHI, Marie-Françoise. " Dire la vérité après la Grande guerre : le combat de Jean Norton Cru ». Dans PERNOT, François, TOUREILLE, Valérie (dir.). Lendemains de guerre... De l'Antiquité au monde contemporain : les hommes, l'espace et le récit, l'économie et le politique. Bruxelles, 2010, p. 185-193.

2. - CRU, op. cit., p. 225 sq. Voir ROUSSEAU, Frédéric. Le procès des témoins de la Grande Guerre. L'affaire Norton Cru. Paris, 2003, passim.

3. - Lettre de Jean Norton Cru à André Pézard, Arch. nat., 691AP 9. Les lettres d'André Pézard à Cru sont conservées dans le fonds Norton Cru des archives municipales de Marseille (46 II). Pézard demeurera en contact épistolaire avec une des sœurs de Cru, Hélène Vogel. Il est à ce titre associé aux échanges qu'elle entretient dans les années 1970 avec le traducteur de l'ouvrage publié par Cru en 1930 sous le titre Du témoignage, Stanley Pincetl - la traduction, publiée en 1976 aux presses universitaires de San Diego, s'intitule War books : a study in historical criticism. Des lettres à Pézard de Pincetl, qui requiert quelques conseils pour la traduction d'extraits de Vauquois, sont conservées dans le fonds Pézard, sous la cote 691 AP 14. Ma gratitude va ici à Silva Fabrizio-Costa, à qui revient la découverte de ces lettres.

4. - Je remercie très chaleureusement la famille d'André Pézard, sa fille Sylvie Pézard, son gendre Daniel Roche et son petit-fils Olivier Roche, donateurs du fonds et dont les témoignages ont permis d'en documenter la constitution; ma gratitude va également à Philippe Lejeune, filleul d'André Pézard mais aussi spécialiste éminent du genre autobiographique. Son intérêt pour les archives Pézard, les recherches qu'il y a effectuées, nos échanges ininterrompus depuis 2012 ont éclairé d'autant la part du fonds spécialement dédiée à la Grande Guerre. Je renvoie à la communication prononcée par Philippe Lejeune le 5 décembre 2014 aux Archives nationales à l'occasion du colloque André Pézard en ses archives.

5. - Les distinctions ici proposées pour les archives 1914-1918 d'André Pézard doivent principalement aux typologies élaborées pour les écrits du for privé. On se référera très utilement, entre autres, à l'article de Christine Nougaret. "Éditer les livres de raison et les journaux ordinaires : l'ecdotique au service de l'historien ». Dans Les écrits du for privé en Europe du Moyen Age à l'époque contemporaine: enquêtes, analyses, publications. Éd. Jean-Pierre Bardet, 
Élisabeth Arnoul et François-Joseph Ruggiu. Bordeaux : Presses universitaires de Bordeaux, 2010, p. 607-612.

6. - 691AP/7, lettres à Hélène, 1ère et 2nde série 1914-1915;691/AP/1/2.1.2. 3e série 1915.

7. - Ce sous-dossier contient entre autres des essais de page de titre et des brouillons de table ; quelques fiches manuscrites ; des notes, écrits et réflexions sur la guerre et la mort (<1917>).

8. - Référence à une lettre envoyée à sa sœur.

9. - Voir Plans de Vauquois : « le Mamelon blanc du 6 au ... mai/15»; «Tranchées allemandes 6 mai 1916 "; Compagnie M, La Maize, cote 185, Bois Carré, par T. Simonnet, 21/1/1916. Plan dessiné à l'encre et aquarellé.

10. - Publiée sous le titre Sturm auf dem Hügel, la traduction, due à Paul Fischamnn, paraît en 1932, à Berlin, chez l'éditeur Bernard Graefe.

11. - Poloniste reconnu, Paul Cazin est l'auteur de L'humaniste à la Guerre, récit publié en 1920. Ses archives, comprenant notamment les lettres de Pézard, sont conservées à la Faculté de Langue et de Lettres Polonaises de l'Université de Varsovie.

12. - Germaniste, Pézard suggère à Fischmann des modifications dont leurs échanges épistolaires témoignent abondamment ; il contracte en outre un abonnement auprès d'une agence de presse qui lui adresse les comptes rendus publiés après la sortie du livre en Allemagne en 1934.

13. - Quoique réservé sur la représentativité des récits de Témoins, Pierre Renouvin (RENOUVIN, Pierre. La crise européenne et la Grande Guerre. Paris : Félix Alcan, 1934) attache en effet, dans le cadre de son travail de classement et du catalogage des fonds de la BDIC, un intérêt majeur à la "psychologie du combattant », via les récits publiés ou inédits de la Grande Guerre, où il fut luimême engagé : voir GILLES, Benjamin. «L'expérience de la guerre dans ses interstices : Pierre Renouvin et la création du fichier "Psychologie du combattant" ». Matériaux pour l'histoire de notre temps, 2010/4 ( $\left.\mathrm{n}^{\circ} 100\right)$, p. 14-20. Le travail de thèse entrepris sous sa direction par Antoine Prost s'inscrit pour partie dans le fil de cette approche. Voir PROST, Antoine. Les Anciens Combattants et la société française (1914-1939). Paris: Presses de la FNSP, 3 vol., 1977 (thèse d'État), et id., Les Anciens Combattants 1914-1940. Paris : Gallimard-Julliard (coll. « Archives »), 1977. A. Prost s'attache cependant, plus que Renouvin, à prendre en compte de manière critique et raisonnée les récits de guerre publiés en les envisageant au prisme de leur réception, désormais interrogeable sur une période significative (plus de quarante ans). PROST, Antoine, WINTER, Jay. Penser la Grande Guerre. Un essai d'historiographie. Paris : Éditions du Seuil, 2004, passim, reviennent, quarante ans après cette première actualisation historiographique, sur les évolutions intervenues durant près d'un siècle dans l'historiographie de la Grande Guerre : elles sont autant le fait d'un changement de régime d'historicité et de l'évolution générationnelle du rapport à la mémoire du premier conflit mondial que de l'accessibilité nouvelle des sources et des matériaux permettant d'évaluer ce rapport. [N.B.: les archives d'Antoine Prost sont conservées aux Archives nationales sous la cote $550 \mathrm{AP}]$.

\section{RÉSUMÉS}

Récemment entré aux Archives nationales, le fonds d'André Pézard (1893-1984) renseigne la vie et les activités professionnelles et littéraires de celui qui fut un des plus grands italianistes de son époque. Ce traducteur de Dante, professeur au Collège de France, est aussi, part moins connue de son œuvre, l'auteur d'un récit publié en 1918 et intitulé Nous autres à Vauquois, où il fait le récit de son expérience dans la Grande Guerre. Les archives de Pézard permettent tout à la fois de 
renseigner les conditions dans lesquelles s'élabore ce texte. Ainsi, les nombreux journaux que tient le jeune Pézard, appelé en 1914, constituent une matrice à partir de laquelle il construira, dès 1917, son récit. Mais à ces notes prises dans les carnets, au jour le jour tout au long de la guerre, s'ajoutent d'autres documents que Pézard « indexe " pour les associer de la manière la plus précise possible au cours des événements vécus : photos, lettres sont ainsi mentionnés, répertoriés dans les carnets. La vie des hommes au quotidien s'éclaire à la lumière de ce faisceau de sources d'une exhaustivité exceptionnelle. Les manuscrits de l'auteur permettent également de suivre le travail de recomposition littéraire auquel il se livre en 1917 et 1918, et tout spécialement de suivre la genèse de Nous autres à Vauquois, presque pas à pas. Pour autant, la mémoire de la guerre ne cesse, et les archives le montrent bien, d'habiter Pézard et d'exiger de lui un travail de documentation et de correction de son propre livre, à l'occasion, notamment, de ses diverses rééditions. Le succès d'estime dont il jouit, notamment auprès d'anciens combattants, lui vaut de recevoir une abondante correspondance - côté français ET allemand, le livre ayant été traduit en Allemagne en 1932. Cette correspondance, soigneusement conservée dans le fonds, témoigne d'une nécessité mémorielle vivement ressentie par toutes les générations touchées par la Grande Guerre. Elle compte aussi quelques pièces qui concernent, quant à elles, la postérité proprement historiographique de Vauquois et de tous les sédiments documentaires successifs qui constituent les archives de guerre d'André Pézard.

The papers of André Pézard (1893-1984) have recently been acquired by the French national archives. They provide rich documentation about the professional and literary activities of one of the most eminent italianists of his day, translator of Dante and professor at the Collège de France. He was also the author of a memoir published in 1918 under the title Nous autres à Vauquois, in which he bears witness to his own experience during the First World War. The archives of André Pézard give us information about the conditions in which he wrote this text. The diaries he had been keeping since his youth and went on writing during the war, form the basis on which his narration was developed after1917. To these diaries, kept in notebooks day by day, he adds several other documents that are 'indexed' in order to associate them as precisely as possible with events he lived through during the war. These photos and letters are mentioned in the diaries. These different sources are remarkably complete and throw much light on the daily life of the soldiers at this time. Pézard's manuscripts also allow us to understand something of the literary re-composition that he worked on between 1917 and 1918. The genesis of Nous autres à Vauquois can be followed practically step by step. Memories of the war never left Pézard, as his archives show, and he pursued the work of documenting and correcting his own book each time it was republished. It was a book which enjoyed considerable success, in particular amongst veterans of the war. Pézard received many letters about it, not only from French people, but also from Germans, since his book was translated into German in 1932. These letters, carefully preserved with Pézard's papers, all suggest how the generations that had lived through the war needed to keep the memory of it. The papers also comprise some documents that throw light on the historiographical posterity of Vauquois and on the long-term accumulation of documents that make up Pézard's war archives. 


\section{INDEX}

Keywords : André Pézard, Jean Norton Cru, Paul Cazin, First World War, diaries, textual genetics, war notebooks, private papers, Vauquois, battle, Nous autres à Vauquois, historians of the First World War, writing, narrative, autobiography, war testimony, private archives, historiography of the First World War

Mots-clés : André Pézard, Jean Norton Cru, Paul Cazin, Grande Guerre, Journaux, Génétique, Carnets de guerre, For privé, Vauquois, Nous autres à Vauquois, historien de la Première Guerre mondiale, Ecriture, Récit, Autobiographie, Témoignage de guerre, archives privées, historiographie de la Grande Guerre

\section{AUTEUR}

\section{ELSA MARGUIN-HAMON}

Conservatrice du patrimoine, Archives nationales, Direction des publics, Département de l'action culturelle et éducative Musée des Archives nationales elsa.marguin@culture.gouv.fr 